\title{
Topographical biomaterials instruct bacterial surface attachment and the in vivo host-pathogen response
}

Manuel Romero ${ }^{1}$, Jeni Luckett $^{1}$, Grazziela Figueredo ${ }^{2}$, Alessandro M. Carabelli ${ }^{3}$, Aurélie Carlier $^{4}$, Aliaksei Vasilevich ${ }^{5}$, Steven Vermeulen ${ }^{4,5}$, David Scurr ${ }^{3}$, Andrew L. Hook ${ }^{3}$, Jean-Frédéric Dubern ${ }^{1}$, Ana C. da Silva ${ }^{1}$, David Winkler ${ }^{6}$, Amir Ghaemmaghami ${ }^{7}$, Jan de Boer ${ }^{5}$, Morgan R Alexander ${ }^{3+}$ and Paul Williams ${ }^{1+*}$

${ }^{1}$ National Biofilms Innovation Centre, Biodiscovery Institute and School of Life Sciences, University of Nottingham, Nottingham, United Kingdom.

${ }^{2}$ School of Computer Science, University of Nottingham, Nottingham United Kingdom

${ }^{3}$ Advanced Materials and Healthcare Technologies Division, School of Pharmacy, University of Nottingham, Nottingham, United Kingdom.

${ }^{4}$ Laboratory for Cell Biology-Inspired Tissue Engineering, MERLN Institute for Technology-

Inspired Regenerative Medicine, Maastricht University, Maastricht, the Netherlands.

${ }^{5}$ BioInterface Science lab, Department of Biomedical Engineering, Eindhoven University of Technology, Eindhoven, the Netherlands.

${ }^{6}$ Department of Biochemistry and Genetics, La Trobe Institute for Molecular Science, La Trobe University, Kingsbury Drive, Melbourne, Victoria 3086, Australia and Monash Institute of Pharmaceutical Sciences, Monash University, Parkville, Australia CSIRO Data61, Pullenvale, Australia,

${ }^{7}$ School of Life Sciences, University of Nottingham, Nottingham, United Kingdom.

${ }^{+}$joint senior authors

*corresponding author 


\section{ABSTRACT}

The prevention of biofilm development on the surfaces of implanted medical devices is a global challenge for the healthcare sector. Bio-instructive materials that intrinsically prevent bacterial biofilm formation and drive an appropriate host immune response are required to reduce the burden of healthcare associated infections. Although bacterial surface attachment is sensitive to micro- and nano- surface topographies, its exploitation has been limited by the lack of unbiased high throughput biomaterial screens combined with model-based methods capable of generating correlations and predicting generic responses. Consequently, we sought to fill this knowledge gap by using polymer chips (TopoChips) incorporating 2,176 combinatorially generated microtopographies. Specific surface topographies exerted a profound impact on bacterial pathogen attachment independent of surface chemistry. A strong correlation between local surface landscape, bacterial attachment and biofilm formation was established using machine learning methods to facilitate analysis of specific surface parameters for predicting attachment. In vitro, lead topographies prevented colonization by motile (Pseudomonas aeruginosa and Proteus mirabilis) and non-motile (Staphylococcus aureus and Acinetobacter baumannii) bacterial pathogens. In a murine foreign body infection model, specific anti-attachment topographies were shown to be refractory to $P$. aeruginosa colonization. 


\section{INTRODUCTION}

Developments in the biomaterials field over the past 25 years (Bhat \& Kumar, 2013) have facilitated the emergence of novel bio-instructive materials with diverse medical applications. These include biomaterials for stimulating appropriate cell proliferation and healing in regenerative medicine, for drug delivery applications, and for fabricating or coating a wide range of medical devices. Consequently, biomaterials now play an important role in practical disease management. Moreover, there is a growing demand for novel biomaterials capable of supporting physiological functions essential for life that improve wellbeing in ageing populations (Holzapfel et al., 2013). Despite the progress made to date, our poor understanding of the intricate interplay and responses of diverse host and microbial cells to surfaces is hampering the rational design of biomaterials. To overcome these limitations, systematic evaluation of desirable biological outcomes by applying high throughput screens and data-driven iterative testing methods have been exploited to gain novel insights into the interactions between specific cell types and materials (Mei et al., 2010; Unadkat et al., 2011; Hook et al., 2012; Epa et al., 2014; Mikulskis et al., 2018). Amid such desirable outcomes, preventing bacterial pathogen attachment and subsequent biofilm formation on implanted medical devices thereby reducing the risk of chronic, persistent infections is an unmet health need (Busscher et al., 2012; Percival et al., 2015). Attempts to prevent such infections have predominantly focused on the incorporation of bactericidal antimicrobials (Zhao et al., 2009; Goodman et al., 2013). However, the main drawbacks of such a strategy is their limited long-term efficacy, the refractory nature of biofilms towards antimicrobial agents and selection for antimicrobial resistance (Swearingen et al., 2016). Alternatively, greater efficacy for the control of microbial biofilms could be achieved by employing biocompatible materials inherently resistant to biofilm formation (Hook et al., 2012; 2013 Dundas et al., 2019). For example, high throughput microarray-based screens have yielded novel polymers capable of preventing biofilm formation by diverse bacterial pathogens in vitro and in vivo in a mouse infection model (Hook et al., 2012; 2013). This work has, in turn, facilitated the development of predictive quantitative structure function relationships for biofilm formation on a range of polymers that have been successfully validated experimentally (Hook et al., 2012; 2013; Epa et al., 2014; Sanni et al., 2015; Mikulskis et al., 2018; Dundas et al., 2019). However, such 
novel materials incur substantial financial costs prior to clinical use as they require extensive toxicity and efficacy studies before regulatory approval can be obtained (Kumar et al., 2016). Consequently, an alternative approach would be to exploit existing materials already approved for use in medical device manufacture. This could involve the introduction for example, of surface topographical features incorporating well-defined shapes and dimensions within the micro- to nano- meter range since both are known to impact on bacterial attachment (Graham \& Cady, 2014; Armentano et al., 2014; Cheng et al., 2019). The difficulty with this strategy resides in the need for previous knowledge of potential bioactive surfaces and the discovery of ways to improve their attachment resistance properties.

Several groups have employed nature-inspired approaches to generate topographies that mimic naturally occurring antifouling surfaces (Cheng et al., 2006; May et al., 2014; Li et al., 2016). For example, a bio-inspired micro-pattern termed Sharklet $\mathrm{AF}^{\mathrm{TM}}$, which emulates the topography of sharkskin scales has been reported to reduce the attachment of bacterial pathogens in vitro including Acinetobacter baumannii, Escherichia coli, Klebsiella pneumoniae, Pseudomonas aeruginosa and Staphylococcus aureus (Chung et al., 2007; Reddy et al., 2011; May et al., 2014). Furthermore, immunocompromised rats with percutaneously implanted Sharklet $\mathrm{AF}^{\mathrm{TM}}$ micropatterned silicone rods infected with S. aureus had lower numbers of bacteria colonizing the rods and fewer bacterial cells in both subcutaneous tissues and spleens compared with those implanted with smooth rods (Xu et al., 2017).

The mechanism(s) by which Sharklet biomimetics reduce microbial attachment raises both biological and physical questions about the nature of these hierarchical topographical interactions. This in turn, has resulted in the development of methods for predicting attachment based on surface topographical features (Schumacher et al., 2008). Among these, the engineered roughness index (ERI) derived from marine spore settlement studies combines surface properties including roughness, number and size of topological design features (Long et al., 2010). However, roughness alone does not capture spatial information including the geometric details, density, periodicity, symmetry or hierarchical arrangement of surface features, many of which a critical role in bacterial attachment (Graham \& Cady, 2014; Cheng et al 2019). Other important 
limitations of the ERI model include predictive accuracy which is restricted to a limited range of feature sizes and so cannot be used to optimize a surface topography.

To address these issues, we have combined a high throughput quantitative method for screening bacterial attachment to micro-topographies on the TopoChip biomaterial library (Unadkat et al., 2011) with machine learning methods to generate robust predictive models. The mathematically designed, randomized TopoChip library of 2,176 different micro-topographies was originally used to identify surface topographies that induced proliferation or osteogenic differentiation of human mesenchymal stromal cells with a view to identifying novel design criteria for improved biomaterials (Unadkat et al., 2011). Here, we describe the generation of predictive models for pathogen attachment using topographical descriptors that relate to geometric elements. From these, we searched for key feature shape parameters that correlate with bacterial attachment that enabled the use of these new predictive models to identify links between topographical patterns and their pro- and anti-attachment properties. Notably, we show that hit topographies were able to reduce bacterial attachment and biofilm formation in vitro and in vivo by pathogens typically associated with implanted medical-device related infections. We show that the bacterial response is surface topography and not surface chemistry dependent and that specific antiattachment topographies are also refractory to $P$. aeruginosa in vivo in a murine foreign body implant infection model. This work illustrates the strength of unbiased screening to uncover previously unperceived bacterial cell-surface interactions and provide strategies for the rational design of novel bio-instructive surfaces.

\section{METHODS}

\section{Bacterial strains and culture conditions}

Bacterial pathogens commonly associated with medical device-associated infections (Percival et al., 2015) chosen for this study included the Gram negatives, P. aeruginosa PAO1-L (Lausanne sub-line), Pr. mirabilis Hauser 1885 and A. baumannii ATCC17978 and the Gram positive, S. aureus SH1000 and are listed in Table S1. Bacteria were routinely grown at $37^{\circ} \mathrm{C}$ in lysogeny broth (LB) or LB agar supplemented with antibiotics as required. Tryptic soy broth (TSB) was used as the growth medium for bacterial TopoChip attachment assays. To mimic in vivo conditions, 
bioRxiv preprint doi: https://doi.org/10.1101/2020.10.10.328146; this version posted January 5, 2021. The copyright holder for this preprint (which was not certified by peer review) is the author/funder, who has granted bioRxiv a license to display the preprint in perpetuity. It is made available under aCC-BY-NC-ND 4.0 International license.

TSB supplemented with $10 \% \mathrm{v} / \mathrm{v}$ human serum (TSBHS10\%) was used for some $P$. aeruginosa experiments. For polyurethane (PU) TopoChip attachment assays, $P$. aeruginosa PAO1-L carrying the constitutively expressed mcherry gene on the plasmid pMMR (Popat et al., 2012) was used to avoid the problem of PU autofluorescence. Cyclic-di-guanylate levels in single cells was quantified using the cdrA::gfp reporter (Rybtke et al., 2012) transformed into $P$. aeruginosa.

\section{Construction of P. aeruginosa PAO1 flagella and type IV pili deletion mutants}

P. aeruginosa PAO1 $\triangle$ fliC and $\triangle$ pilA mutants were constructed via 2-step allelic exchange obtained by double crossover as previously described (Hook et al., 2019). Two PCR products amplifying the upstream and the downstream nucleotide regions of each gene were generated using the primer pair 1FW/1RW and 2FW/2RW, respectively (Table S1). Both PCR products were fused by overlapping PCR to create a deletion in the corresponding gene. The resulting fragment was cloned into the suicide plasmid pME3087 (Table S1). The integration of the suicide plasmid into the $P$. aeruginosa chromosome was carried out by conjugation. Recombinants were selected on tetracycline $\left(125 \mu \mathrm{g} \mathrm{ml}^{-1}\right)$. The second cross over event was carried out using the carbenicillin enrichment method (300 $\mathrm{g} \mathrm{ml}^{-1}$ ) to select for the loss of tetracycline resistance by plating the resulting colonies on LB supplemented with or without tetracycline. The in-frame deletions were confirmed by PCR and DNA sequence analysis and their phenotypes confirmed by swimming and twitching motility assays (Morris et al., 2013; Hook et al., 2019).

\section{TopoChip fabrication}

The TopoChip was designed by randomly selecting 2,176 features from a large in silico library of features containing single or multiple $10 \mu \mathrm{m}$ high pillars within a virtual square of either 10 by 10,20 by 20 , or 28 by $28 \mu \mathrm{m}^{2}$ size (Unadkat et al., 2011). Micro-pillars were constructed from three different microscale primitive shapes: circles, triangles and rectangles ( $3 \mu \mathrm{m}$ widths). Topographies were assembled as periodical repetitions of the features within $290 \times 290 \mu \mathrm{m}$ microwells (TopoUnits - TUs) surrounded by $40 \mu \mathrm{m}$ tall walls in a $66 \times 66$ array containing a duplicate TU for each topography together with flat control surfaces. TopoChips were fabricated on a $2 \times 2$ $\mathrm{cm}^{2}$ chip divided into four quadrants as previously described (Unadkat et al., 2011; Zhao et al., 2017). Briefly, the inverse structure of the topographies was produced in silicon by standard photolithography and deep reactive etching. This silicon mould was then used to make a positive 
mould in poly(dimethylsiloxane) (PDMS) from which a second negative mould in OrmoStamp hybrid polymer (micro resist technology Gmbh) was fabricated. This served as the mould for hot embossing polystyrene (PS), polyurethane (PU) and cyclic olefin copolymer (COC) films to produce TopoChips with 3 different surface chemistries. After fabrication the arrays were subjected to oxygen plasma etching to ensure the same surface chemistry over each chip was maintained for each of the three polymers. Fig. S1 shows examples of TU micro-topographies.

\section{Surface chemical analysis}

The surface chemistry of the TopoChips was assessed using time-of-flight secondary ion mass spectrometry (ToF-SIMS) and X-ray photoelectron spectroscopy (XPS). ToF-SIMS measurements were conducted on an ION-ToF IV instrument using a monoisotopic $\mathrm{Bi}_{3}{ }^{+}$primary ion source operated at $25 \mathrm{kV}$ and in 'bunched mode'. TopoChip surface chemistry was quantified in terms of elemental composition using an Axis-Ultra XPS instrument (Kratos Analytical, UK) with a monochromated Al ka X-ray source $(1486.6 \mathrm{eV})$ operated at $10 \mathrm{~mA}$ emission current and $12 \mathrm{kV}$ anode potential $(120 \mathrm{~W})$. Small spot aperture mode was used in magnetic lens mode (FoV2) to measure a sample area of approximately $110 \mu \mathrm{m}^{2}$. CasaXPS (version 2.3.18dev1.0x) software was used for quantification and spectral modelling. The measured $\mathrm{N}$ 1s fraction for growth medium serum-conditioned surfaces was converted into protein layer thickness using Ray \& Shard (2011) relationship between $[\mathrm{N}]$ and protein depth.

\section{TopoChip screen for bacterial attachment and viability}

Prior to incubation with bacteria, TopoChips were washed by dipping in distilled water and sterilized in $70 \% \mathrm{v} / \mathrm{v}$ ethanol. The air-dried chips were placed in petri dishes $(60 \mathrm{~mm} \times 13 \mathrm{~mm})$ and incubated statically or with shaking $(60 \mathrm{rpm})$ at $37^{\circ} \mathrm{C}$ in $10 \mathrm{ml}$ of growth medium inoculated with diluted (optical density: $\mathrm{OD}_{600 \mathrm{~nm}}=0.01$ ) bacteria from overnight cultures. Static incubation was selected for screening experiments as this produced consistent bacterial attachment while reducing the formation of biofilm streamers on TopoChip corners which can induce cross contamination of TUs under flow (Rusconi et al., 2010). At specific time points, TopoChips were removed and washed in phosphate buffered saline (PBS) pH 7.4 to remove loosely attached cells. After rinsing with distilled water, attached cells were stained with Syto9 (50 $\mu \mathrm{M}$; Molecular Probes, 
Life Technologies) for $30 \mathrm{~min}$ at room temperature. After staining, TopoChips were rinsed with distilled water, air-dried and mounted on a glass slide using Prolong antifade reagent (Life Technologies). The viability of attached cells was evaluated by fluorescent staining with the LIVE/DEAD® BacLight ${ }^{\top M}$ bacterial viability kit (Molecular Probes, Life Technologies).

\section{TopoChip imaging and data acquisition}

TopoChips were imaged using a Zeiss Axio Observer Z1 microscope (Carl Zeiss, Germany) equipped with a Hamamatsu Flash 4.0 CMOS camera and a motorized stage for automated acquisition. A total of 4,356 images (one per TU) were acquired for each chip using a $488 \mathrm{~nm}$ laser as light source. Since the bacterial cells may attach at different heights on the micropatterns, images were initially acquired as $50 \mu \mathrm{m}$ range Z-stacks ( $2 \mu \mathrm{m}$ steps - 25 slides) from the TUs using a $40 \times$ objective (Zeiss, LD Plan-Neofluar 40×/0.6 Korr Ph 2 M27). Although this method facilitates capture of the total fluorescence emitted by bacteria attached to the topographies, it significantly increased scanning times and file sizes ( 460 GB per chip). Hence, a lower $\times 10$ magnification lens (Zeiss, EC Plan-Neofluar $10 \times / 0.30 \mathrm{Ph} 1$ ) was routinely used as it provided sufficient depth resolution for capturing the total fluorescence per TU. This enabled the use of the auto-focus function, which considerably reduced scanning times and file sizes per TopoChip. Cropping the images into a smaller field of view (247 $\mu \mathrm{m} \times 247 \mu \mathrm{m})$ and omitting the walls of the micro-wells reduced the artefacts arising from bacterial attachment to the walls and further improved the auto-focus function.

To identify out-of-focus images from each TopoChip dataset, individual topographical images were combined into composites using open source Fiji-Image] 1.52p software (National Institutes of Health, US). To improve TopoChip dataset quality, image pre-processing also included a) staining artefact removal by excluding pixels with fluorescence intensities higher than 63,000 from data acquisition and b) assay-specific background fluorescence was removed using flat control TUs as a reference.

To classify topographies influencing bacterial attachment, the mean fluorescence intensity on each TU was measured using Fiji-ImageJ. Hit micro-topographies with anti-attachment properties 
were selected for further studies based on the screening data obtained from quantifying $P$. aeruginosa $(n=22)$ and S. aureus $(n=6)$ attachment to PS TopoChips (Fig. S1). Additionally, and to discriminate between bacterial responses to hit topographies with other patterned surfaces, TUs with similar or a small increases in attachment with respect to flat controls ("proattachment TUs") were also selected for further investigation. To ascertain that hit surfaces influenced the observed bacterial responses, two-way ANOVA with Dunnett's multiple comparisons tests were applied to determine whether bacterial attachment on TUs differed significantly from that of a flat control $(p<0.05)$ when compared with the variations within the replicates using GraphPad Prism 8.0 (GraphPad Software, Inc., San Diego, CA).

\section{Bacterial single-cell tracking}

To track single bacterial cells interacting with flat, pro- and anti-attachment TUs, an inverted TE2000 microscope (Nikon, Japan) equipped with a Hamamatsu Orca Flash 4.0v2 sCMOS camera and an OKOLab cage incubation system to maintain temperature $\left(37^{\circ} \mathrm{C}\right)$ and humidity constant (95\%) was used. Differential interference contrast (DIC) brightfield imaging was carried out using a single channel white MonoLED (Cairns) light source and a 40x objective (Nikon, CFI Plan Fluor $40 \times / 1.3)$. Experiments were conducted using a custom designed single well holder in static growth conditions (Carabelli et al 2020). Coverslips were sealed with a silicone and halogen free high-vacuum grease (Apiezon M). To obtain single bacterial cell tracking data, previously developed bespoke MATLAB scripts were employed. To measure bacterial population density above selected topographies, time series z-stacks (40 $\mu \mathrm{m}$ range - $2 \mu \mathrm{m}$ steps) were acquired every min for $4 \mathrm{~h}$ from selected TUs. To avoid sample disturbance an optical relay was used to recreate the sampling area virtually, facilitating rapid scanning in the z-dimension using a remote piezo-driven objective (Hook et al, 2019)

\section{Generation of predictive surface topography attachment models}

To define the surface design parameters that influence bacterial attachment, the data acquired from screening $P$. aeruginosa and $S$. aureus on PS TopoChips were interrogated as follows. The fluorescence values for bacterial attachment to each of the replicate TUs were normalized to the average fluorescence intensity of the chip quadrant to account for differences in staining 
intensities between experiments. The fluorescence intensity was established to correlate with the number of attached fluorescent bacteria as shown previously (Hook et al., 2012). It was therefore used as the dependent variable in the models. TUs with low signal to noise ratios $(<2)$ were excluded from the datasets of $P$ aeruginosa (342 units removed) and $S$ aureus attachment (93 units removed). The XGBoost machine learning method (Chen and Guestrin, 2016) was applied to generate relationships between the topographies and bacterial attachment using the topographical descriptors listed in Table S2. The XGBoost module was used with default parameters in Python 3.7. Seventy percent of each bacterial attachment dataset was used to train the model, and $30 \%$ were kept aside to determine the predictive power of the model. The SHAP (SHapley Additive exPlanations) package in Python 3.7 (Lundberg and Li, 2017) was used to eliminate less informative descriptors and to determine descriptor importance. The 2,176 unique micro-topographies on the TopoChip were labelled as follows: T2-XX-aabb, where T2 indicates the version of the TopoChip design, XX the substrate material (e.g. PS), aa the array row number (ranging from 01 to 33 ) and $b b$ the column number (ranging from 01 to 66 ). Importantly, the flat surface control topography was positioned at the top left corner prior to TopoChip imaging, to allow consistent identification of each TU.

\section{Murine foreign body infection model}

To investigate the progress of bacterial infection and the host immune response to pro- (T2-PU1228, T2-PU-2056) and anti- (T2-PU-0709, T2-PU-1307, T2-PU-1429 and T2-PU-2153) attachment TUs, a murine foreign body infection model was used (Hook et al, 2012). TUs (3 mm x $7 \mathrm{~mm}$ ) with micro-patterns imprinted on one side were fabricated in PU. Using a 9 gauge trocar needle, rectangular sections of scaled up PU-TUs were implanted subcutaneously (1 per mouse, 3 repeats for each micropattern topography), into 19-22 g female BALB/c mice (Charles River) with the patterned side facing upwards to the skin surface. One hour before implantation, 2.5 $\mathrm{mg} / \mathrm{kg}$ of Rymadil analgesic (Pfizer) was administered by subcutaneous injection. Animals were anaesthetized using isoflurane, the hair on one flank removed by shaving and the area sterilized with Hydrex Clear (Ecolab). After foreign body insertion, mice were allowed to recover for 4 days prior to injection of either $1 \times 10^{5}$ colony forming units (CFUs) of $P$. aeruginosa or vehicle (phosphate buffered saline; uninfected control). 
Mice were housed in individually ventilated cages under a $12 \mathrm{~h}$ light cycle, with food and water ad libitum, and with weight and clinical condition of the animals recorded daily. Four days post infection, the mice were humanely killed and the micropatterned PU TU samples and the surrounding tissues removed. PU TU samples were fixed in $10 \% \mathrm{v} / \mathrm{v}$ formal saline and labelled with antibodies targeting CD45 (pan-leukocyte marker; VWR violetfluor 450), CD206 (macrophage mannose receptor; Biorad rat anti-mouse antibody conjugated to Alexa 647) and the membrane-selective dye FM1-43 (Thermofisher Scientific) for total TU-associated biomass. Bacterial cells on the micropatterned surfaces were visualized with polyclonal antibodies raised against $P$. aeruginosa (Thermofisher Scientific). Secondary antibodies used were goat anti-rabbit (quantum dot 705; Thermofisher). Images were taken on a Zeiss 700 confocal microscope and fluorescence data quantified using Image J. All animal work was approved following local ethical review at University of Nottingham and performed under U.K. Home Office Project Licence $30 / 3082$.

\section{RESULTS}

\section{P. aeruginosa and S. aureus PS TopoChip screens}

To ensure that the bacteria-material interactions observed are specifically dependent on surface topography, PS TopoChips were subjected to time-of-flight secondary ion mass spectrometry (ToF-SIMS) together with X-ray photoelectron spectroscopy (XPS) for quantitative elemental analysis. The results obtained (Supplementary section; Fig. S2) indicate that the surfaces to be used for screening have uniform chemistry and were suitable for investigating specific responses to micro-topographies. The screening strategy used for $P$. aeruginosa and $S$. aureus attachment to PS TopoChips is illustrated in Fig. 1a. The $4 \mathrm{~h}$ incubation time and static conditions at $37^{\circ} \mathrm{C}$ selected provided a sufficiently stringent assay for the identification of topographies with low and high initial bacterial cell attachment. $P$. aeruginosa attachment to TUs on the PS TopoChip $(n=$ 22) revealed a wide range of micro-topographies exhibiting variable resistance to bacterial attachment, with a strong selection for specific micro-topographies (Fig. 1b and c). For S. aureus (Figs. 1b and d), although clear fluorescence intensity differences with $P$. aeruginosa were 
observed for a series of TopoChip TUs (Fig. S3), similar attachment patterns and good TUattachment correlations were observed $(n=6)$. Interestingly, most micro-patterns on the PS TopoChip showed reduced bacterial attachment with respect to the flat control, especially for $S$. aureus where only $\sim 4 \%$ of the topographies exhibited increased cell attachment (Fig. 1b). This was unexpected since the presence of narrow grooves and cavities is known to support bacterial retention on surfaces under static growth conditions (Whitehead \& Verran, 2006; Shi \& Zhu, 2009). These findings suggested that by modifying surfaces with well-defined micro-topographies, early cell attachment and subsequent biofilm formation could be prevented. Consistent with previous studies evaluating $P$. aeruginosa and $S$. aureus attachment to topographically defined surfaces such as Sharklet AF ${ }^{\mathrm{TM}}$ (Graham \& Cady, 2014; Chung et al., 2007), microscale pillar size and channel width appeared to support bacterial cell attachment only to certain topographies in the TopoChip array. By visual inspection of the high and low-adhering topographies it appeared that less bacterial cells attached to topographies with smaller features displaying narrower spacing (see examples of anti- and pro- attachment TUs in Fig. S1).

\section{Defining micro-topographical parameters determining bacterial attachment}

CellProfiler analysis of images of the TU design provided 242 topographical shape descriptors (Unadkat et al, 2011). Descriptors with Pearson correlations above 0.85 were eliminated, resulting in 68 which were used to train $P$. aeruginosa and $S$. aureus attachment models. The full set of topographical descriptors used for modelling is listed in Table S2. The Extreme Gradient Boosting (XGBoost) machine learning regression method was used to identify correlations between the topographies and bacterial attachment, producing good models for the datasets.

The performance of the $P$ aeruginosa attachment model is shown in Fig. $\mathbf{2 A}$, and the results for S. aureus are shown in Fig. 2E. The contributions of the descriptors found to be the most important for each model are shown in Fig. 2B for $P$. aeruginosa and in Fig. 2F for $S$ aureus. There were strong correlations between the machine learning model predictions versus observed attachment values in the test sets for both bacterial species models, with $R^{2}=0.82$ and root mean square error (RMSE) 0.27 log fluorescence for $P$ aeruginosa and $R^{2}=0.79$ and RMSE 0.20 
$\log$ fluorescence for S. aureus (Figs. $\mathbf{2 C}$ and $\mathbf{2 G}$ ). These models were trained using the ten most significant surface parameters identified by the descriptor selection machine learning method. The spaces between objects (inscribed circle radii) and the area of the topographical features (both the total area and the area of the pillars) were two of the most important factors for predicting bacterial attachment. Specifically, features with a mean area $<5 \mu \mathrm{m}^{2}$ and inscribed circle radii of $>4 \mu \mathrm{m}$ were associated with the highest $P$. aeruginosa attachment (Fig. S4A). For S. aureus, high attachment was associated with pillars with pattern areas of $<10 \mu \mathrm{m}^{2}$, with a maximum inscribed circle of $>4.5 \mu \mathrm{m}$ (Fig. S4B). We plotted bacterial fluorescence intensity against the dominant topography descriptor identified (standard deviation of the inscribed circles radii) to ascertain its predictive power alone. The resulting linear models had an $R^{2}$ of 0.49 and RMSE 0.25 for predicting $P$. aeruginosa attachment and an $R^{2}$ of 0.63 and RMSE 0.14 for predicting S. aureus attachment, indicating the importance of these descriptors in predicting bacterial colonisation (Figs. 2D and 2H). The lower significance descriptors (average inscribed circle radii, and average topography pattern area) provided multiple solutions influenced by the values chosen for the feature dimensions (Fig. S4).

For biomedical purposes, topographies associated with low pathogen attachment and biofilm formation are of particular interest. The regression model coefficients show the magnitude and sign of the topographical feature descriptors contributions to the attachment models. Topographical descriptors with large negative coefficients are associated with low pathogen attachment (Figs. 2B and $\mathbf{2 F}$ ). For $P$. aeruginosa, the average compactness of the pattern, the total area occupied by primitives and the mean maximum radius of the pattern reduced pathogen attachment (Fig 2B). For S. aureus, the results indicate that the total area occupied by primitives and changes in the feature over the diagonal was negatively correlated with attachment.

\section{Micro-topography, bacterial attachment and biofilm formation}

Based on the screening data obtained from quantification of $P$. aeruginosa and $S$. aureus attachment to PS TUs, hit topographies ("anti-attachment TUs") with a 5 to 20-fold reduction in bacterial attachment compared with the flat control surface were chosen for further studies. To contrast bacterial responses to hit topographies with other patterned surfaces, TUs with similar 
or a slight increase in attachment with respect to flat controls ("pro-attachment TUs") were also selected (Fig. S1). Fig. 3 presents representative images (Fig. 3a) and quantitative data (Fig. 3b) for $P$. aeruginosa, S. aureus, Pr. mirabilis and $A$. baumannii grown under static conditions for $4 \mathrm{~h}$ and shows that all four pathogens respond similarly to the pro- (T2-PS-1228 and T2-2327) and anti- (T2-PS-0709 and T2-PS-1307) attachment TUs.

To further validate the selected TUs, $P$. aeruginosa attachment was quantified after growth under flow and with the TopoChip arrays inverted in the bacterial cultures. These conditions were used to remove the contribution of bacterial cell settlement due to gravitational effects and requires that the bacterial cells move towards the topographies and actively seek suitable niches for attachment. The data obtained (Figs. $4 \mathbf{a}$ and $\mathbf{b}$ ) show that the hit topographies maintained their P. aeruginosa pro- and anti-attachment properties independent of TopoChip orientation and flow.

Furthermore, $P$. aeruginosa and S. aureus were grown for $24 \mathrm{~h}$ to promote biofilm formation on micro-patterned and flat surfaces followed by confocal imaging and image analysis. The antiattachment TUs T2-PS-0709 and 1307 showed more than 15-fold (two-way ANOVA, $p<0.0001$ ) average reduction of $P$. aeruginosa biofouling respectively (Figs. $4 \mathbf{c}$ and $\mathbf{d}$ ). Mature biofilms incorporating interconnecting bacterial aggregates were observed on the pro-attachment TUs, T2-PS-1228 and T2-PS-2327 as well as on the flat control, while the few cells present on the antiattachment TUs T2-PS-0709 and T2-PS-1307 were much more dispersed (Figs. 4c and d). Similar results were also obtained for $S$. aureus with 5-fold (two-way ANOVA, $p<0.0001$ ) average reduction of biofilm growth on the two anti-attachment TUs over a $24 \mathrm{~h}$ period when compared with the flat control surface (Fig. 4c and d).

To confirm that the differences in bacterial attachment to hit TUs are derived from surface topography rather than chemistry, TopoChips supporting enhanced or reduced $P$. aeruginosa attachment were fabricated in the medical device relevant polymers, polyurethane (PU) and cyclic olefin copolymer (COC). Remarkably, the selected micro-topographies fabricated in both materials showed similar attachment levels to those in PS arrays providing further evidence that surface 
topography strongly influences bacterial attachment independent of surface chemistry (Figs. 4a and $\mathbf{b})$.

\section{Single cell tracking and real time surface colonisation analysis}

Since the lack of bacterial cell attachment observed on the anti-TUs could be a consequence of either surface avoidance or detachment following initial attachment, the behaviour of $P$. aeruginosa was captured on flat and micro-patterned surfaces using time-lapse microscopy under static growth conditions. Live imaging and single cell tracking analysis revealed a substantial reduction in the number of early (after $3.5 \mathrm{~h}$ ) surface colonizing $P$. aeruginosa cells on an antiattachment topography (T2-PS-1307) compared with a flat or a pro-attachment TU (T2-PS-1960) (Fig. 5a). Given the bactericidal activity previously described for various textured surfaces (Ivanova et al., 2012; Hasan et al., 2018; Wu et al., 2018) and to determine whether a similar mechanism was responsible for the reduced colonisation of anti-attachment TUs by $P$. aeruginosa, the viability of cells attached to the selected micropatterns was evaluated using live/dead differential bacterial cell staining. No significant changes in cell viability for the selected topographies was apparent (Fig. S5) indicating that neither topography had a bactericidal effect on the attached $P$. aeruginosa cells that would explain the differences in surface colonisation. To determine whether the non-motile Gram-positive S. aureus behaved similarly, the experiment was repeated under the same conditions. In contrast to $P$. aeruginosa, no significant differences in the number of staphylococci accumulating on the flat, pro- and anti- attachment TU surfaces colonisation was observed (Fig. 5b). However, in contrast to $P$. aeruginosa on the antiattachment TU, staphylococcal cells were observed to settle on both the gaps between and tops of the micropillars.

To investigate whether $P$. aeruginosa cells differentially accumulate similarly in the bulk medium immediately above the flat, pro- and anti- attachment TUs, $40 \mu \mathrm{m}$ image stacks above the selected TU surfaces were captured after $3 \mathrm{~h}$ exposure and the cell population densities quantified. A significantly lower number of swimming $P$. aeruginosa cells was consistently recorded above the anti-attachment TU surface compared with the pro-attachment and flat surfaces (Fig. S6). 
In contrast, no differences in population cell density over the topographies were recorded for $S$. aureus over the same TUs (Fig. S6).

For $P$. aeruginosa, flagella and type IV pili and the second messenger, cyclic diguanylate (c-diGMP) are involved in motility, surface sensing and biofilm development (Schniederberend et al., 2019). To determine whether the two surface appendages were involved in discriminating between flat and surface topographies, type IV pili $(\Delta p i l A)$ and flagella $(\Delta f l i C)$ mutants were constructed by allelic replacement. Fig. 5 (panels $\mathbf{c}$ and $\mathbf{d}$ ) shows that in common with the $P$. aeruginosa parental strain, mutants lacking type IV pili $(\Delta$ pilA) or flagella $(\Delta f l i C)$ both exhibit a substantial reduction in the number of early (after $3.5 \mathrm{~h}$ ) surface colonizing cells on an antiattachment topography (T2-PS-1307) compared with a flat or a pro-attachment TU (T2-PS-1960) as quantified using live imaging. Similar results were obtained by quantifying fluorescence intensity after $4 \mathrm{~h}$ (Fig. 5e). However, image analysis (Fig. 5f) revealed that while neither the parent strain nor the $\triangle$ pilA or $\triangle$ fliC mutants colonized the anti-attachment TU, differences in the colonization profile of the pro-attachment TU are clearly apparent. While neither type IV pili nor flagella are essential for colonization of the pro-attachment topographical micropillars of T2-PS1960, the lack of type IV pili results in microcolony segregation (Fig. 5f).

Since c-di-GMP signalling is key to bacterial 'leave' or 'stay' decision making, we transformed $P$. aeruginosa with a cdrA::gfp fusion that has been validated as a reporter for intracellular c-diGMP levels (Rybtke et al., 2012). Fig.5g shows that there is significantly less fluorescence from cells associated with an anti-attachment TU and hence produce much less c-di-GMP than those associated with flat or pro-attachment TUs.

\section{In vivo assessment of pro and anti-attachment topographies in a murine foreign body infection model}

To determine whether surface conditioning by serum proteins influences the interactions of bacterial cells with pro- and anti- attachment TUs as well as to mimic in vivo conditions, we grew P. aeruginosa in TSBHS10\% or TSB and compared attachment to flat, pro- and anti-attachment TUs after incubation at $37^{\circ} \mathrm{C}$ for $4 \mathrm{~h}$. Fig. $\mathbf{S 2}$ shows that serum protein layers of similar thickness 
as quantified using XPS were deposited on the pro- and anti- attachment TUs. The comparative attachment behaviours of $P$. aeruginosa on the flat, pro- and anti- attachment TUs were not affected by serum protein deposition (Fig. S7).

To explore the in vivo host response and bacterial attachment resistance, pro- and antiattachment TUs were implanted subcutaneously into mice which, after recovery, were inoculated with either $P$. aeruginosa or PBS (uninfected control). After 4 days, the TUs were removed and their micro-topographical integrity confirmed by scanning electron microscopy (Fig. S8). The semi-quantitative bacterial attachment and host response data are summarized in Table $\mathbf{1}$ and illustrated by Fig S9. No bacterial cells were detected on the uninfected control TUs. These data contrast with the infected pro-attachment TUs (T2-PU1228 and T2-PU2056) where P. aeruginosa cells were clearly detectable and a robust host response observed. Much lower levels of both $P$. aeruginosa and host cells were apparent on anti-attachment TUs such as T2-PU1307 after removal from the infected animals (Table 1 and Fig. S9).

\section{DISCUSSION}

Microscale surface topographic features may promote or inhibit bacterial attachment and subsequent biofilm formation, depending on the shape, size and density of the features. However, the interplay between bacterial cells and topographical landscapes is relatively poorly understood and involves both the physical and chemical nature of the surfaces as well as bacterial surface sensing mechanisms (Graham \& Cady, 2014; Wu et al., 2018; Chang et al., 2019). Attachment of bacteria to micro-topographies is also known to be dependent on hydrodynamics, surface wettability, ordering and segregation of bacterial cells and chemical conditioning of the surface (Cheng et al., 2019). While the physical mechanisms involved in determining whether or not bacteria attach differ in terms of topographical scale, most studies have focused on a limited number of topographical designs. This approach has previously restricted our ability to explore model-based methods to derive correlations and predict bacterial responses on the basis of surface properties. To address these limitations and to discover new micro-topographies that 
bioRxiv preprint doi: https://doi.org/10.1101/2020 10.10.328146; this version posted January 5, 2021. The copyright holder for this preprint (which was not certified by peer review) is the author/funder, who has granted bioRxiv a license to display the preprint in perpetuity. It is made available under aCC-BY-NC-ND 4.0 International license.

prevent bacterial attachment in the context of medical device-associated infections, we screened the 2,176 micro-topographies on TopoChip arrays against two different pathogens, $P$. aeruginosa and S. aureus. These screens were coupled with active machine learning approaches such that biological outcomes could be correlated with the surface design criteria and iterative testing undertaken to facilitate optimization of 'hit' topographies. The large number of unique microtopographies evaluated and the remarkably strong correlation found between local landscape and attachment for both pathogens, enabled detailed analysis of the relevance of underlying surface design parameters on biological responses. This approach facilitated the prediction of bacterial attachment from surface design criteria rather than from individual physical surface traits such as surface roughness or hydrophobicity since these have not resulted in the elucidation of general principles underlying the impact of surface topography on bacterial attachment (Graham \& Cady, 2014; Wu et al, 2018; Cheng et al, 2019).

For biomedical device applications, surface topographies associated with low pathogen attachment and biofilm formation are required. Our results from the regression model coefficients inform the magnitude of the topographical feature descriptors contributing to bacterial attachment. Those with large negative coefficients were associated with low levels of attachment. The most important descriptors found include the inscribed circle radius which relates to the space between features, the area of the topological features and the average compactness of the pattern area. Moreover, similar biological performance was recorded for 'hit' micro-patterns fabricated in three different polymer materials incubated under different conditions indicating that the changes observed in bacterial attachment depend on the topographical features rather than surface chemistry. Remarkably, we observed that in these in vitro experiments with a motile Gramnegative organism ( $P$. aeruginosa), and a non-motile Gram-positive organism (S. aureus) similar surface descriptors dominated for both species. The responses of $A$. baumanni and Pr. mirabilis to selected pro- and anti-attachment TUs were also very similar to those of $P$. aeruginosa and $S$. aureus. These findings could not have been anticipated from our current understanding of bacteria-surface interactions. Consequently, they illustrate the strength of unbiased screening of large topographical libraries to reveal previously unperceived cell-surface interactions as well as 
providing insights towards the rational fabrication of new bioactive surfaces (Magennis et al., 2015; Vermeulen \& de Boer, 2020).

Most of the TUs on the PS TopoChip array reduced bacterial attachment with respect to the flat control, especially for S. aureus where very few topographies exhibited increased cell attachment. This was unexpected since the presence of narrow grooves and cavities has been reported to support bacterial retention on surfaces under static growth conditions (Whitehead \& Verran, 2006; Shi \& Zhu, 2009). These findings suggest that by modifying surfaces with well-defined microtopographies, early cell attachment and subsequent biofilm formation can be prevented. Consistent with other studies (Graham \& Cady, 2014; Chung et al., 2007), evaluating P. aeruginosa and S. aureus attachment to micro-topographies, microscale pillar size and channel width appear to support bacterial cell attachment to some but not to other TUs in our array experiments.

Real time imaging of selected topographies exposed to growing bacterial cultures showed that $P$. aeruginosa and $S$. aureus cells could access all niches available within the micro-topographies selected. This was anticipated since bacterial attachment is known to depend on both the width and spacing of the topographical features within a pattern and the size of the microbial cell (Cheng et al 2019). However, the feature sizes encountered by the bacteria on the TopoChip are significantly larger than bacterial cells $(10,20$ or $28 \mu \mathrm{m})$. These observations suggest that the changes in attachment to different TUs observed are not simply related to bacterial cells being unable to access certain topographical areas but to the cells sensing and responding in different ways to the TU niches available. Interestingly, single cell tracking showed a significant reduction in early surface coloniser cells of $P$. aeruginosa on an anti-attachment topography while no noticeable differences in surface occupation between flat, pro- and anti-attachment TUs was recorded for the non-motile S. aureus. In contrast to earlier studies reporting topographies with growth inhibitory effects (Ivanova et al., 2012; Hasan et al., 2018; Wu et al., 2018), no obvious changes in bacterial cell viability for the selected TUs was apparent. This finding indicated that neither topography killed the attached $P$. aeruginosa cells and so explain the differences in surface colonisation observed. Moreover, a lower number of swimming $P$. aeruginosa cells was quantified over the anti-attachment surface compared with flat and pro-attachment TUs, whereas no 
differences in cell population density over the same TUs were recorded for $S$. aureus. This suggests that physical obstruction of bacterial cell access to the topographies is not responsible for the variable attachment observed. Therefore, for $P$. aeruginosa surface sensing and/or a failure to switch from reversible to irreversible attachment (Petrova and Sauer, 2012) on the antiattachment micro-topographies are more likely explanations for the differences in biological behaviour observed. Consistent with this hypothesis, $P$. aeruginosa cells colonising an antiattachment TU showed cdrA expression levels well below of cells on flat and pro-attachment TUs. This suggests that intracellular levels of c-di-GMP could be important in regulating bacterial responses to micro-topographies and merits further investigation. Changes in the level of this second messenger, implicated in irreversible attachment and biofilm development via control of exopolysaccharide production (Schniederberend et al., 2019), have previously been linked to surface mechanical cues (Persat et al., 2015; Song et al., 2018). Indeed, variations in attachment-stimulated surface sensing driven by surface stiffness and porosity modulate c-diGMP levels in P. aeruginosa, with both flagella and type IV pili involved in this process (Petrova \& Sauer, 2012). Although our results showed alterations in colonisation and attachment to microtopographies by $P$. aeruginosa type IV pilus $(\Delta p i l A)$ and flagellum $(\triangle f l i C)$ mutants, supporting a role for these appendages in exploration and adhesion to micro-topographically defined surfaces (Friedlander et al., 2013), a similar reduction in an anti-attachment TU colonisation was observed for these less motile mutants compared with the parental strain. This together with the fact that $P$. aeruginosa wildtype cells can move freely in and out of the spaces between features and neighbouring niches within the TUs, again suggests that the anti-adhesive properties exhibited by the hit TUs are related to differences in the strength of attachment to different niches within the topographies.

To determine whether the pro- and anti-attachment properties of the TUs were maintained in complex environments where the TU surfaces are likely to be conditioned by host proteins and cells, we examined their response to $P$. aeruginosa after conditioning with human serum in vitro or after subcutaneous implantation into mice in vivo. In both cases, the anti-attachment properties were maintained suggesting that the deposition of host proteins and cells does not alter the biofilm resistant properties of the anti-attachment TUs. Consequently, these micro- 
topographies have considerable potential for preventing biofilm formation in a clinical context. Texturizing the surface of clinically approved biomaterials would have the benefit of retaining their physical and mechanical properties while significantly reducing the cost of new materials discovery and commercial development. In addition, since material topography is known to influence macrophage attachment and phenotype (Vassey et al 2020), this work raises the exciting prospect of exploiting micro-topographies to modulate host immune responses and prevent both biofilm-centred infections and prevent foreign body rejection of implanted medical devices. 


\section{ACKNOWLEDGEMENTS}

This work was supported by the Engineering and Physical Sciences Research Council [grant nos. EP/N006615/1 and EP/K005138/1] the Wellcome Trust [grant nos. 103882 and 103884], the Biotechnology and Biological Sciences Research Council [BB/R012415/1], the Dutch Science Foundation (NWO) [grant VENI 15075], and the Dutch province of Limburg. We thank Dr Emily F Smith at the Nanoscale and Microscale Research Centre (NMRC - University of Nottingham) for acquiring XPS spectra and Dr Marta M Paino with XPS data interpretation. TopoChips were imaged in the School of Life Sciences Imaging Unit (SLIM - University of Nottingham). We thank Nick Beijer and Nadia Roumans for TopoChip fabrication assistance, Chris Gell and Arsalan Latif for their help with data acquisition.

\section{AUTHORS' CONTRIBUTIONS}

$M A, J d B$ and PW conceived the project. MR and $\mathrm{JL}$ designed and conducted the in vitro and in vivo experiments respectively. GF, AuC, AV and DW conducted the modelling and the machine learning. AC performed the single-cell tracking and surface colonisation analysis. SV fabricated the TopoChip arrays, DS analysed the TU surface chemistry, JD constructed the mutants, MR, MA and PW wrote the manuscript with input from all other authors

\section{COMPETING INTERESTS STATEMENT}

We have no competing interests.

\section{BIBLIOGRAPHY}

1. Bhat S, Kumar A. Biomaterials and bioengineering tomorrow's healthcare. Biomatter $2013 ; 3(3): \mathrm{e} 24717$.

2. Holzapfel BM, Reichert JC, Schantz JT, Gbureck U, Rackwitz L, Nöth U, Jakob F, Rudert M, Groll J, Hutmacher DW. How smart do biomaterials need to be? A translational science and clinical point of view. Adv Drug Deliv Rev 2013;65(4):581-603.

3. Mei Y, Saha K, Bogatyrev SR, Yang J, Hook AL, Kalcioglu ZI, Cho SW, Mitalipova M, Pyzocha N, Rojas F, Van Vliet KJ, Davies MC, Alexander MR, Langer R, Jaenisch R, 
Anderson DG. Combinatorial development of biomaterials for clonal growth of human pluripotent stem cells. Nat Mater 2010;9(9):768-78.

4. Unadkat HV, Hulsman M, Cornelissen K, Papenburg BJ, Truckenmüller RK, Carpenter AE, Wessling M, Post GF, Uetz M, Reinders MJ, Stamatialis D, van Blitterswijk CA, de Boer J. An algorithm-based topographical biomaterials library to instruct cell fate. Proc Natl Acad Sci 2011;108(40):16565-70.

5. Hook AL, Chang CY, Yang J, Luckett J, Cockayne A, Atkinson S, Mei Y, Bayston R, Irvine DJ, Langer R, Anderson DG, Williams P, Davies MC, Alexander MR.

Combinatorial discovery of polymers resistant to bacterial attachment. Nat Biotechnol $2012 ; 30(9): 868-875$.

6. Epa VC, Hook AL, Chang C, Yang J, Langer R, Anderson DG, Williams P, Davies MC, Alexander MR and Winkler DA. Modelling and Prediction of Bacterial Attachment to Polymers. Adv Funct Mater 2014;24(14):2085-2093.

7. Mikulskis $P$, Hook A, Dundas AA, Irvine D, Sanni O, Anderson D, Langer R, Alexander MR, Williams P, Winkler DA. Prediction of Broad-Spectrum Pathogen Attachment to Coating Materials for Biomedical Devices. ACS Appl Mater Interfaces 2018;10(1):139149.

8. Busscher $\mathrm{HJ1}$, van der Mei HC, Subbiahdoss G, Jutte PC, van den Dungen JJ, Zaat SA, Schultz MJ, Grainger DW. Biomaterial-associated infection: locating the finish line in the race for the surface. Sci Transl Med 2012;4(153):153rv10.

9. Percival SL, Suleman L, Vuotto C, Donelli G. Healthcare-associated infections, medical devices and biofilms: risk, tolerance and control. J Med Microbiol 2015;64:323-34.

10. Zhao L, Chu, PK, Zhang Y, Wu Z. Antibacterial coatings on titanium implants. J Biomed Mater Res B Appl Biomater. 2009;91(1):470-80.

11. Goodman SB, Yao Z, Keeney M, Yang F. The future of biologic coatings for orthopaedic implants. Biomaterials 2013;34(13):3174-3183.

12. Swearingen MC, Granger JF, Sullivan A, Stoodley P. Elution of antibiotics from poly(methyl methacrylate) bone cement after extended implantation does not necessarily clear the infection despite susceptibility of the clinical isolates. Pathog Dis 2016;74(1):ftv103. 
13. Hook AL, Chang C-Y, Yang J, Atkinson S, Langer R, Anderson DG, Davies MC, Williams P, Alexander MR. Discovery of novel materials with broad resistance to bacterial attachment using combinatorial polymer microarrays. Adv Mater 2013;25:2542-2547.

14. Dundas AA, Sanni O, Dubern JF, Hook AL, Irvine DJ, Williums P, Alexander MR. Validating a Predictive Structure-Property Relationship by Discovery of Novel Polymers Which Reduce Bacterial Biofilm Formation. Adv Mater 2019;31:1903513.

15. Sanni O, Chang CY, Anderson DG, Langer R, Davies MC, Williams PM, Williams P, Alexander MR, Hook AL. Bacterial attachment to polymeric materials correlates with molecular flexibility and hydrophilicity. Adv Healthc Mater 2015;4(5):695-701.

16. Kumar S, Raj S, Sarkar K, Chatterjee K. Engineering a multi-biofunctional composite using poly(ethylenimine) decorated graphene oxide for bone tissue regeneration. Nanoscale 2016;8(12):6820-36.

17. Graham MV, Cady NC. Nano and microscale topographies for the prevention of bacterial surface fouling. Coatings 2014;4(1):37-59.

18. Armentano I, Arciola CR, Fortunati E, Ferrari D, Mattioli S, Amoroso CF, Rizzo J, Kenny JM, Imbriani M, Visai L. The interaction of bacteria with engineered nanostructured polymeric materials: a review. ScientificWorldJournal 2014;2014:410423.

19. Cheng Y, Feng G, Moraru CI. Micro- and Nanotopography Sensitive Bacterial Attachment Mechanisms: A Review. Front Microbiol 2019;10:191.

20. Cheng YT, Rodak DE, Wong CA, Hayden CA. Effects of micro- and nano-structures on the self-cleaning behaviour of lotus leaves. Nanotechnology $2006 ; 17(5): 1359-62$.

21. May RM, Hoffman MG, Sogo MJ, Parker AE, O'Toole GA, Brennan AB, Reddy ST. Micropatterned surfaces reduce bacterial colonization and biofilm formation in vitro: Potential for enhancing endotracheal tube designs. Clin Transl Med 2014;3:8.

22. Li X, Cheung GS, Watson GS, Watson JA, Lin S, Schwarzkopf L, Green DW. The nanotipped hairs of gecko skin and biotemplated replicas impair and/or kill pathogenic bacteria with high efficiency. Nanoscale 2016;8(45):18860-18869.

23. Chung KK, Schumacher JF, Sampson EM, Burne RA, Antonelli PJ, Brennan AB. Impact of engineered surface microtopography on biofilm formation of Staphylococcus aureus. Biointerphases 2007;2(2):89-94. 
24. Reddy ST, Chung KK, McDaniel CJ, Darouiche RO, Landman J, Brennan AB.

Micropatterned surfaces for reducing the risk of catheter-associated urinary tract infection: an in vitro study on the effect of sharklet micropatterned surfaces to inhibit bacterial colonization and migration of uropathogenic Escherichia coli. J Endourol $2011 ; 25(9): 1547-52$.

25. Xu B, Wei Q, Mettetal MR, Han J, Rau L, Tie J, May RM, Pathe ET, Reddy ST, Sullivan L, Parker AE, Maul DH, Brennan AB, Mann EE. Surface micropattern reduces colonization and medical device-associated infections. J Med Microbiol 2017;66(11):1692-1698.

26. Schumacher JF, Long CJ, Callow ME, Finlay JA, Callow JA, Brennan AB. Engineered nanoforce gradients for inhibition of settlement (attachment) of swimming algal spores. Langmuir 2008;24(9):4931-7.

27. Long CJ, Schumacher JF, Robinson PA 2nd, Finlay JA, Callow ME, Callow JA, Brennan AB. A model that predicts the attachment behavior of Ulva linza zoospores on surface topography. Biofouling 2010;26(4):411-9.

28. Popat R, Crusz SA, Messina M, Williams P, West SA, Diggle SP. Quorum-sensing and cheating in bacterial biofilms. Proc Biol Sci 2012;279(1748):4765-71.

29. Rybtke MT, Borlee BR, Murakami K, Irie Y, Hentzer M, Nielsen TE, Givskov M, Parsek MR, Tolker-Nielsen T. Fluorescence-based reporter for gauging cyclic di-GMP levels in Pseudomonas aeruginosa. Appl Environ Microbiol 2012;78(15):5060-9.

30. Hook AL, Flewellen JL, Dubern JF, Carabelli AM, Zaid IM, Berry RM, Wildman RD, Russell N, Williams P, Alexander MR. Simultaneous Tracking of Pseudomonas aeruginosa Motility in Liquid and at the Solid-Liquid Interface Reveals Differential Roles for the Flagellar Stators. mSystems $2019 ; 4(5)$.

31. Morris ER, Hall G, Li C, Heeb S, Kulkarni RV, Lovelock L, Silistre H, Messina M, Cámara M, Emsley J, Williams P, Searle MS. Structural rearrangement in an RsmA/CsrA ortholog of Pseudomonas aeruginosa creates a dimeric RNA-binding protein, RsmN. Structure $2013 ; 21(9): 1659-71$.

32. Zhao Y, Truckenmuller R, Levers M, Hua WS, de Boer J, Papenburg B. High-definition micropatterning method for hard, stiff and brittle polymers. Mater Sci Eng C Mater Biol Appl 2017;71:558-564. 
33. Ray S, Shard AG. Quantitative analysis of adsorbed proteins by x-ray photoelectron spectroscopy. Anal Chem 2011;83(22):8659-66.

34. Rusconi R, Lecuyer S, Guglielmini L, Stone HA. Laminar flow around corners triggers the formation of biofilm streamers. J R Soc Interface 2010;7(50):1293-9.

35. Chen T, Guestrin C. XGBoost: A Scalable Tree Boosting System. arXiv 2016. 1603.02754 [Cs.LG]

36. Lundberg SM, Li S-I. A unified approach to interpreting model predictions. In Advances in Neural Information Processing Systems, 2017. Pp 4765-4774.

37. Whitehead KA, Verran J. The effect of surface topography on the retention of microorganisms. Food Bioprod Process 2006;84(4):253-259.

38. Shi X, Zhu X. Biofilm formation and food safety in food industries. Trends Food Sci Technol 2009;20(9):407-413.

39. Ivanova EP, Hasan J, Webb HK, Truong VK, Watson GS, Watson JA, Baulin VA, Pogodin S, Wang JY, Tobin MJ, Löbbe C, Crawford RJ. Natural bactericidal surfaces: mechanical rupture of Pseudomonas aeruginosa cells by cicada wings. Small. 2012;8(16):248994.

40. Hasan J, Jain S, Padmarajan R, Purighalla S, Sambandamurthy VK, Chatterjee K. Multi-scale surface topography to minimize adherence and viability of nosocomial drugresistant bacteria. Mater Des. 2018;140:332-344.

41. Wu S, Zuber F, Maniura-Weber K, Brugger J, Ren Q. Nanostructured surface topographies have an effect on bactericidal activity. J Nanobiotechnology. $2018 ; 16(1): 20$.

42. Schniederberend M, Williams JF, Shine E, Shen C, Jain R, Emonet T, Kazmierczak BI. Modulation of flagellar rotation in surface-attached bacteria: A pathway for rapid surface-sensing after flagellar attachment. PLoS Pathog 2019;15(11):e1008149.

43. Magennis EP, Hook AL, Davies MC, Alexander C, Williams P, Alexander MR. Engineering serendipity: High-throughput discovery of materials that resist bacterial attachment. Acta Biomater 2016;34:84-92.

44. Vermeulen S, de Boer J. Screening as a strategy to drive regenerative medicine research. Methods 2020. pii: S1046-2023(19)30280-4. 
45. Persat A, Inclan YF, Engel JN, Stone HA, Gitai Z. Bacterial mechanotransduction using type IV pili. Proc Natl Acad Sci 2015;112(24):7563-7568.

46. Song F, Wang H, Sauer K, Ren D. Cyclic-di-GMP and oprF Are Involved in the Response of Pseudomonas aeruginosa to Substrate Material Stiffness during Attachment on Polydimethylsiloxane (PDMS). Front Microbiol 2018;9:110.

47. Petrova OE, Sauer K. Sticky situations: key components that control bacterial surface attachment. J Bacteriol 2012;194:2413-2425.

48. Friedlander RS, Vlamakis H, Kim P, Khan M, Kolter R, Aizenberg J. Bacterial flagella explore surface topography. Proc Natl Acad Sci 2013;110(14):5624-5629.

49. Vassey MJ, Figueredo GP, Scurr DJ, Vasilevich AS, Vermeulen S, Carlier A, Luckett J, Beijer NRM, Williams P, Winkler DA, de Boer J, Ghaemmaghami AM, Alexander MR. Immune Modulation by Design: Using Topography to Control Human Monocyte Attachment and Macrophage Differentiation. Adv Sci (Weinh). 2020 7(11):1903392.

50. Carabelli AM, Isgro M, Sanni O, Figueredo GP, Winkler, DA, Burroughs L, Blok AJ, Dubern, J-F, Pappalardo F, Hook AL, Williams P, Alexander MR. Single cell tracking on polymer microarrays reveals the impact of surface chemistry on Pseudomonas aeruginosa twitching speed and biofilm development. ACS Applied Bio Materials revised version submitted. 
Table 1. Host cellular response to pro- and anti-attachment Topo-units in mice infected with $P$. aeruginosa.

\begin{tabular}{|l|c|c|c|c|c|}
\multicolumn{1}{c}{} & \multicolumn{2}{c}{ P. aeruginosa } & Fm1-43 & CD206 & CD45 \\
\cline { 2 - 6 } & Feature ID & $\begin{array}{c}\text { Bacterial } \\
\text { Detection }\end{array}$ & $\begin{array}{c}\text { Total } \\
\text { Cell } \\
\text { Biomass }\end{array}$ & Macrophages & Leucocytes \\
\hline Pro- & T2-PU-1228 & ++ & +++ & ++ & +++ \\
attachment & T2-PU-2056 & +++ & +++ & ++ & +++ \\
\hline \multirow{4}{*}{ Anti- } & T2-PU-0709 & - & + & + & +++ \\
attachment & T2-PU-1307 & - & + & + & +++ \\
& T2-PU-1429 & + & ++ & + & +++ \\
& T2-PU-2153 & + & ++ & + & ++ \\
Control - no & T2-PU-1307 & - & + & $+/-$ & + \\
bacteria & T2-PU-1429 & - & + & $+/-$ & + \\
\hline
\end{tabular}

- , not detected; + , low level; ++ , intermediate; +++ , high level; see Fig. S9 for examples of the corresponding confocal fluorescence microscopy images. Data from 3 TUs per microtopography combined. 


\section{FIGURES}

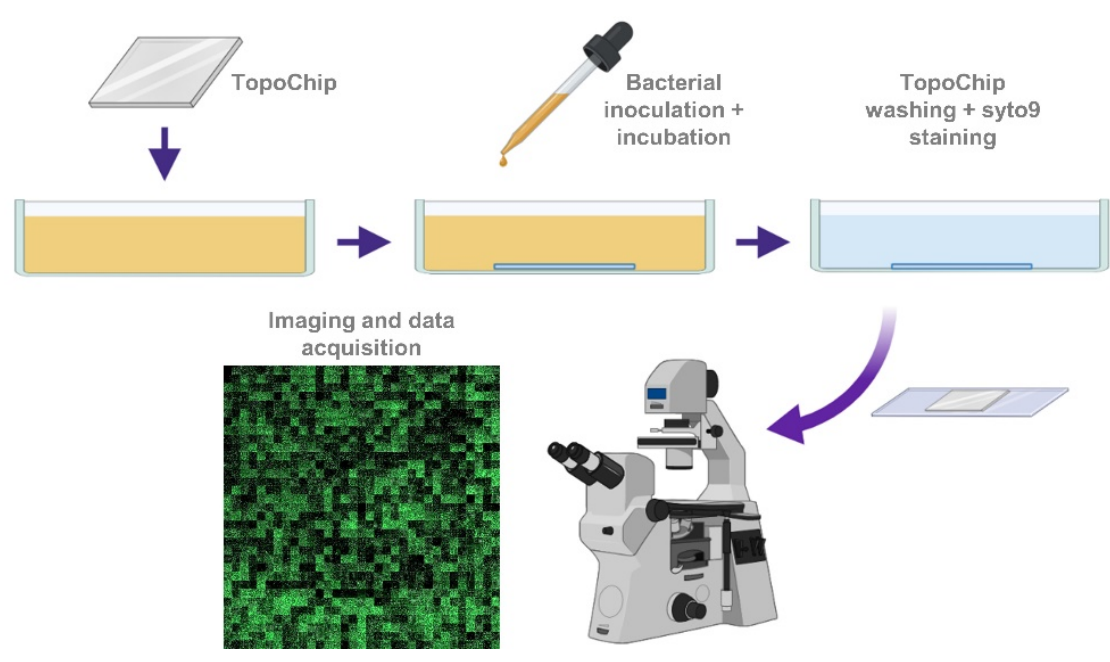

b

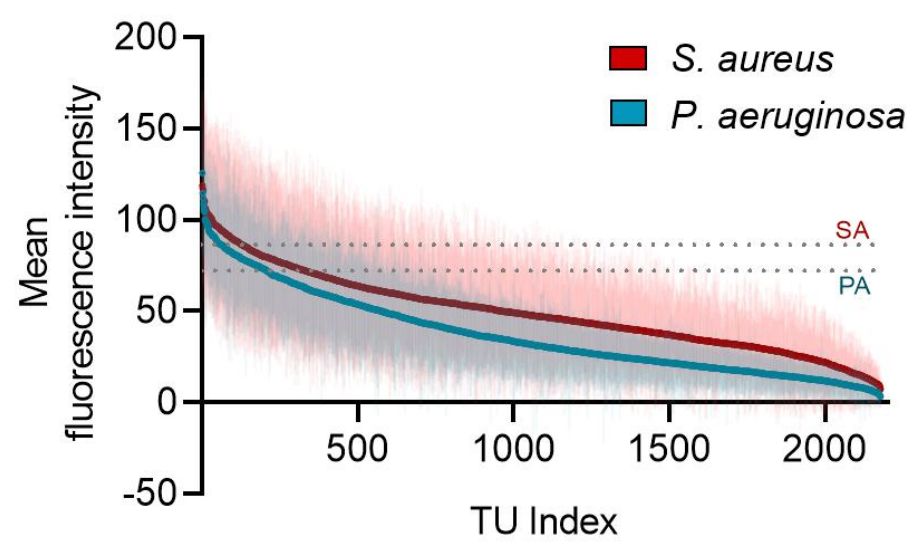

C

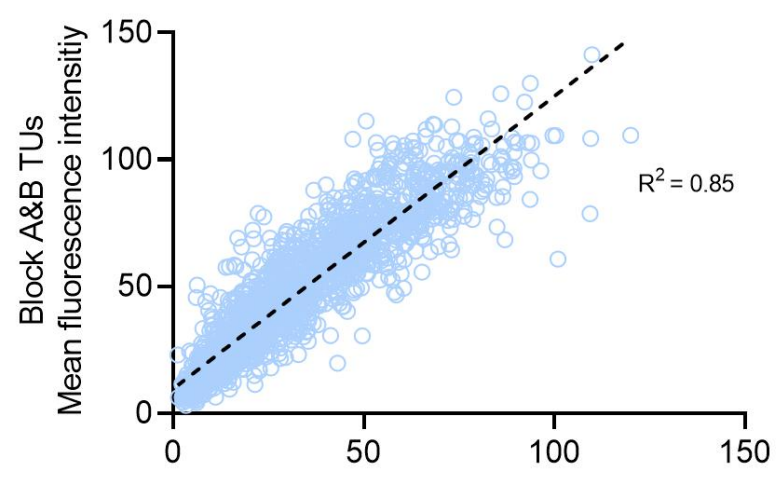

Block $A_{i} \& B_{i}$ TUs Mean fluorescence intensitiy d

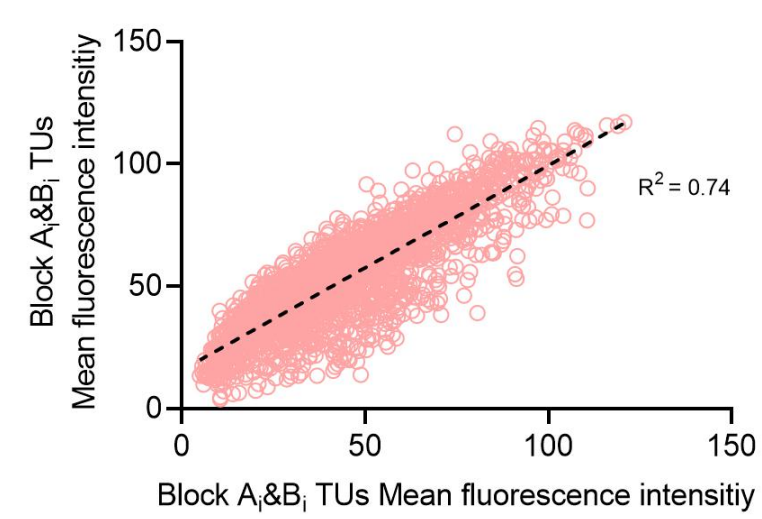

Figure 1. (a) Bacterial attachment assay procedure. (b) Ranking of topographies according to the mean fluorescence intensity per TU after $P$. aeruginosa and $S$. aureus attachment to PS TopoChips ( $n=22$ and $n=6$ respectively). The dotted line corresponds to the mean fluorescence value of the flat surface control for each species. (c, d) Scatter plots representing mean fluorescence intensities from $P$. aeruginosa $(n=22)(\mathbf{c})$ and $S$. aureus $(n=6)(\mathbf{d})$ cells attached to replicate TUs from PS TopoChips. 


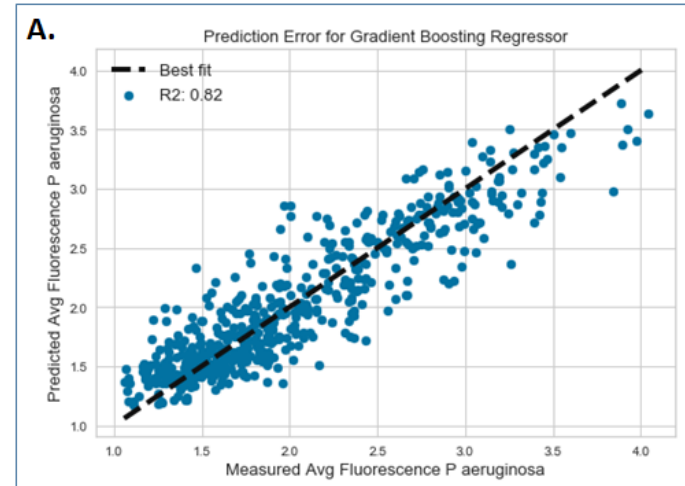

B.
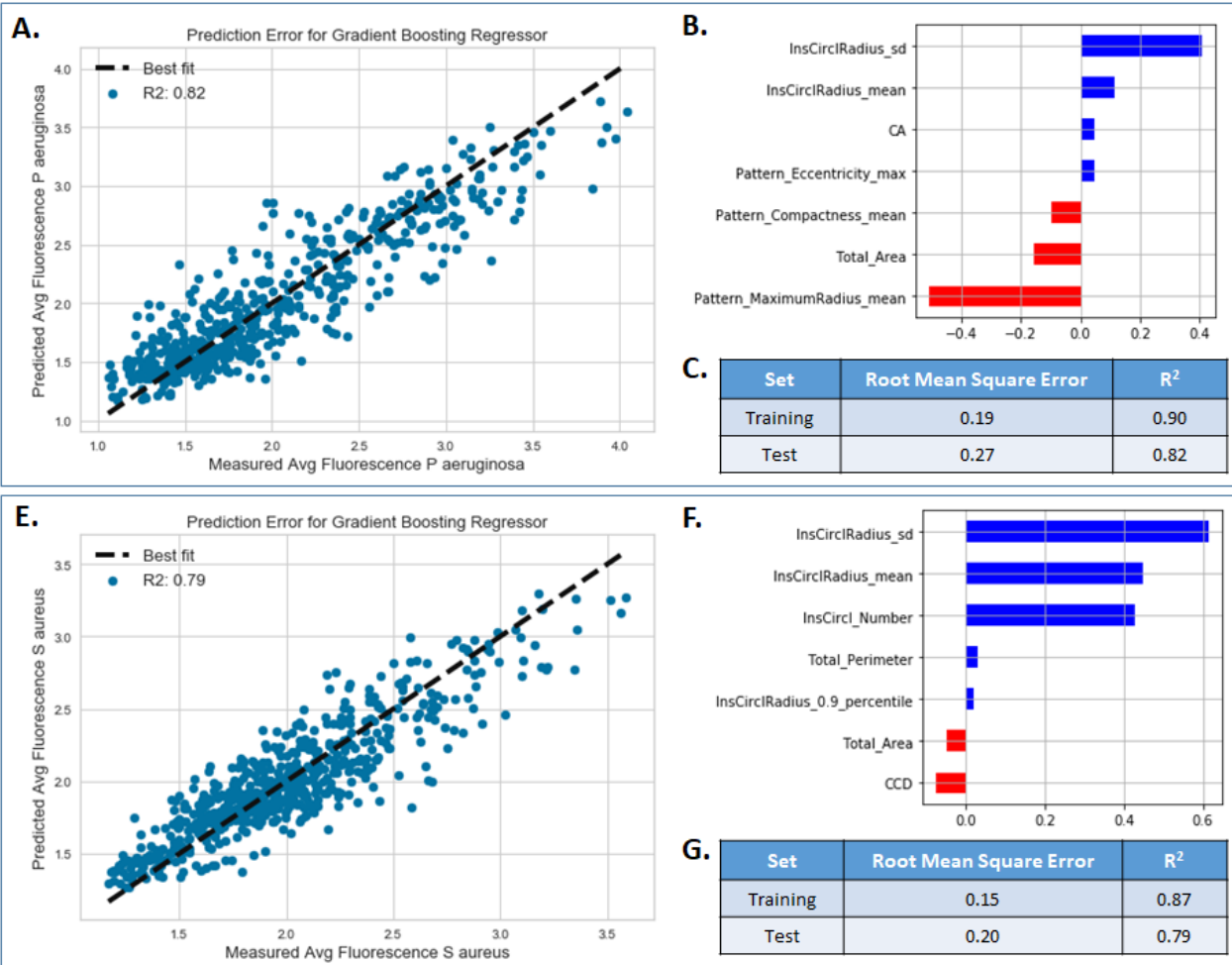

F.

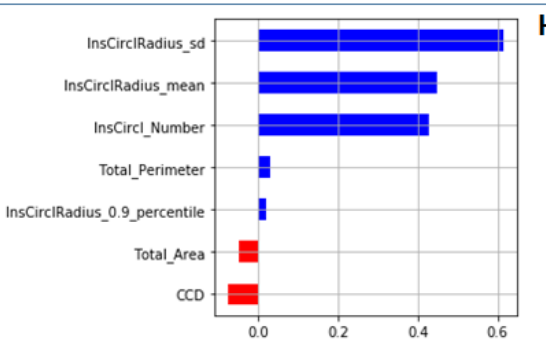

G.

\begin{tabular}{|c|c|c|}
\hline Set & Root Mean Square Error & $\mathbf{R}^{2}$ \\
\hline Training & 0.15 & 0.87 \\
\hline Test & 0.20 & 0.79 \\
\hline
\end{tabular}
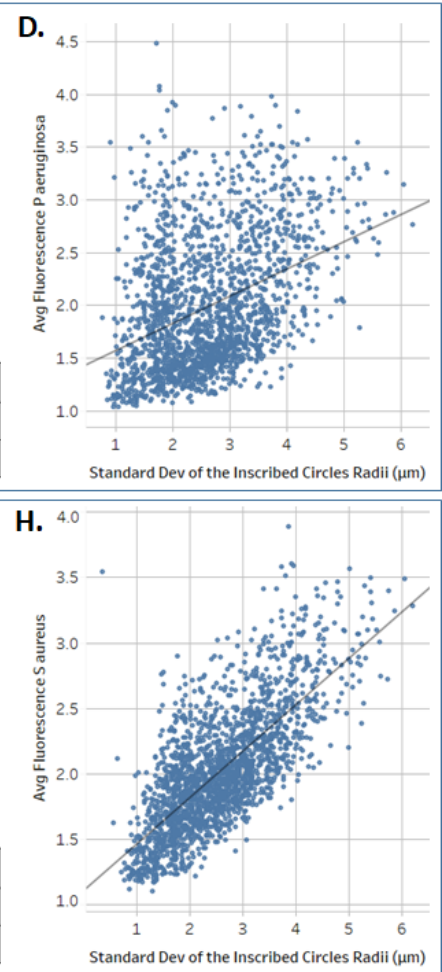

Figure 2 - Machine learning modelling results for pathogen attachment using XGBoost: (a) Scatter plot of the measured against predicted log attachment values for the $P$. aeruginosa test set, (b) $P$. aeruginosa descriptors importance, (c) Regression model performance metric results for $P$. aeruginosa training and test sets, and (d) Scatter plot of the standard deviation of the inscribed circles radii of the topographies; (e) Scatter plot of the measured against predicted log attachment values for the $S$. aureus test set, (f) $S$. aureus descriptors importance, ( $\mathbf{g})$ Regression model performance metric results for the $S$. aureus training and test sets, and (h) Scatter plot of the standard deviation of the inscribed circles radii of the topographies. The topographical descriptors found to be most important for bacterial attachment are the inscribed circle (in the figure denoted InsCircl descriptors), which relate to the space between primitives and the total area covered by primitives. 
a

S. aureus

Pr. mirabilis
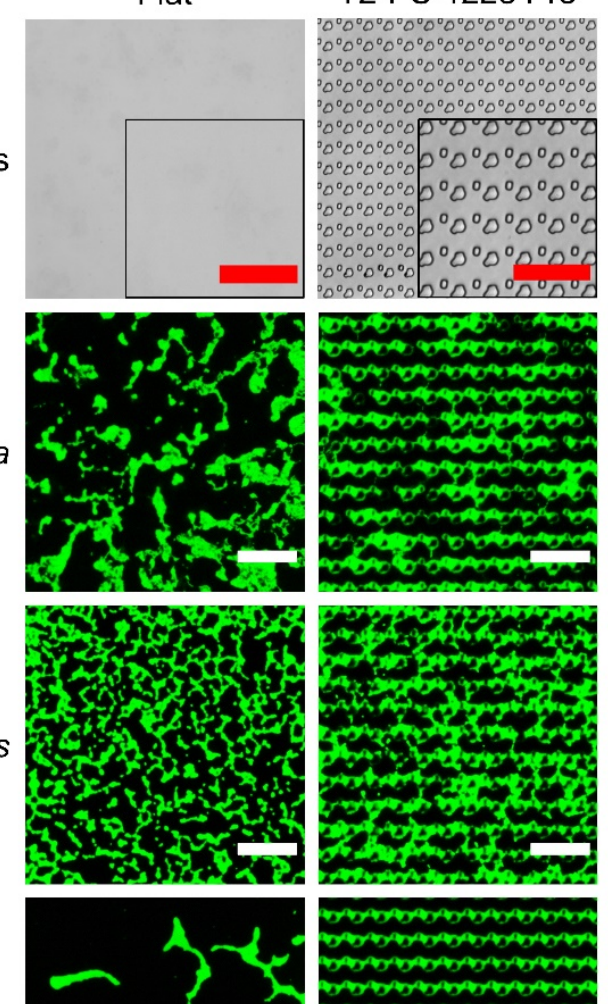

A. baumannii
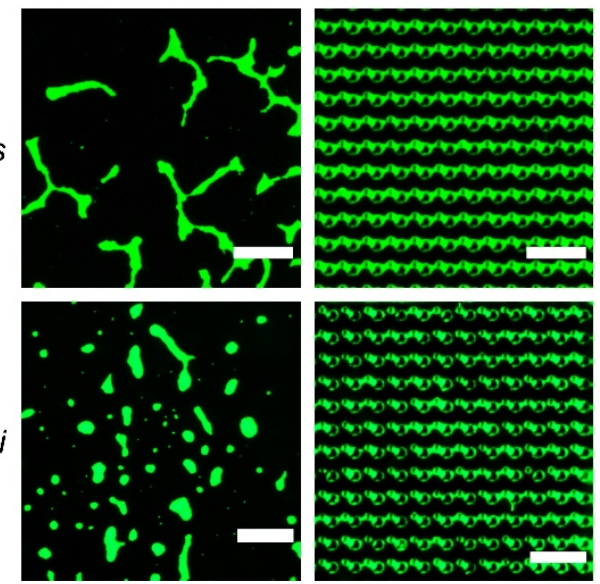

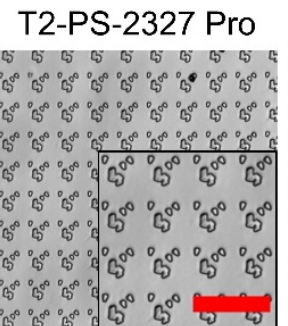

T2-PS-0709 Anti T2-PS-1307 Anti
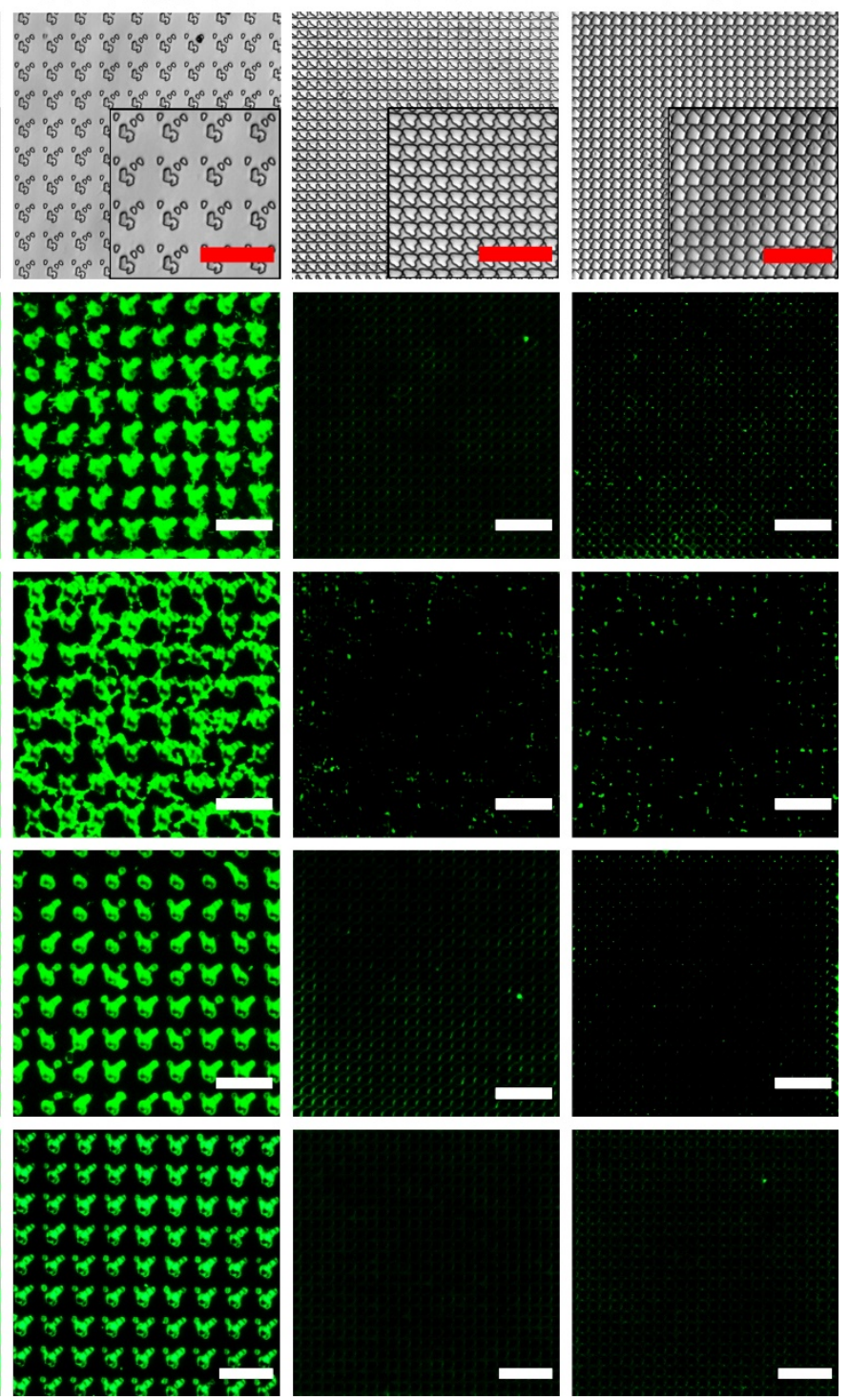

b

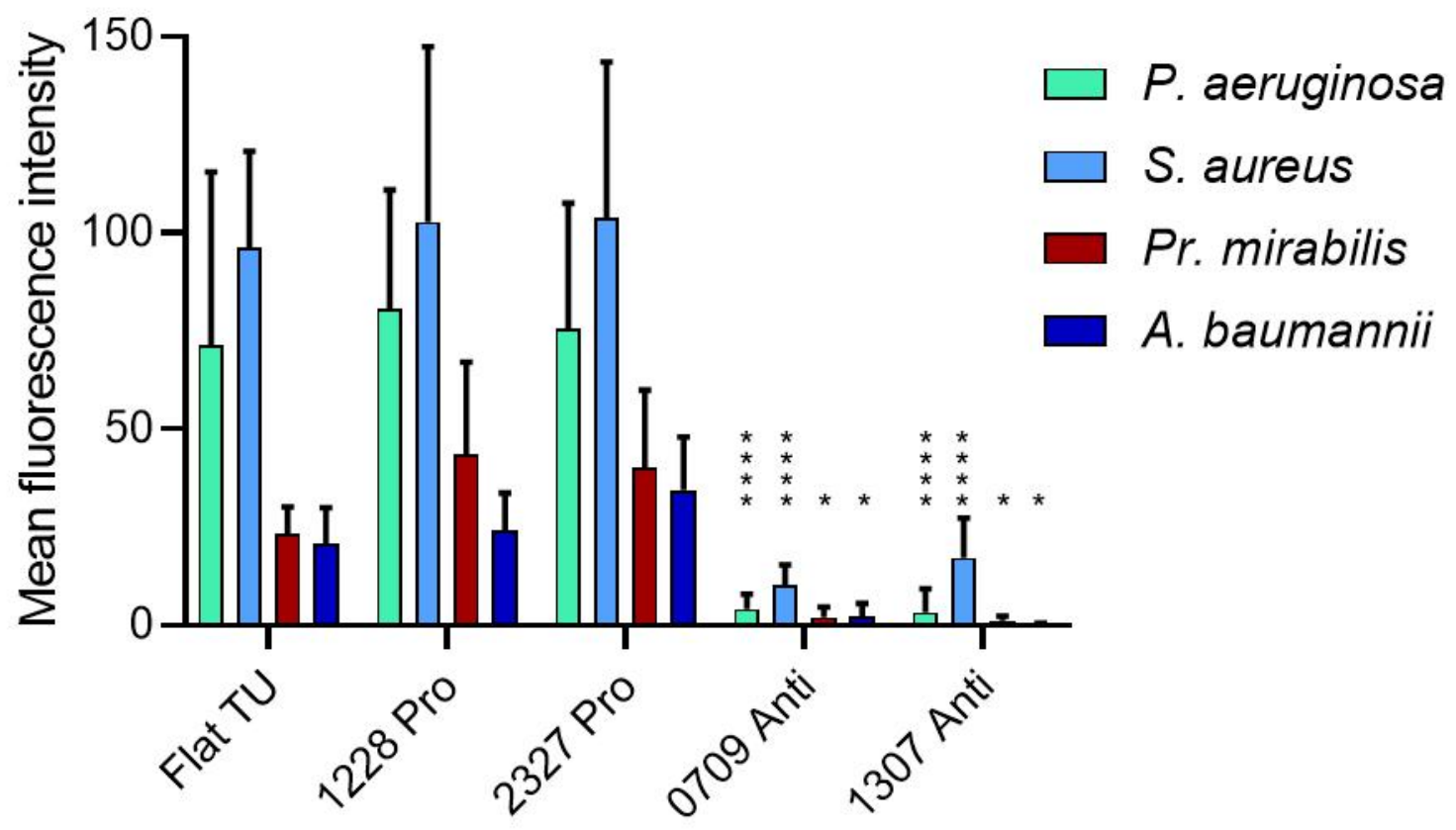


Figure 3 (a) Representative images of $P$. aeruginosa, S. aureus, Pr. mirabilis and A. baumannii attachment to flat, pro- and anti-attachment TUs (bright field images shown in top row) from PS TopoChips after $4 \mathrm{~h}$ incubation under static conditions with planktonic bacteria. (b) Quantification of mean fluorescence intensity for $P$. aeruginosa, $S$. aureus, $\mathrm{Pr}$. mirabilis and $A$. baumannii cells stained with Syto9 and grown on the same TUs from PS TopoChips. Scale bar: $50 \mu \mathrm{m}$. Data shown are mean $\pm S D, n \geq 6$. Statistical analysis was done using a two-way ANOVA with Dunnett's multiple comparisons test (* $p<0.05 ; * * p<0.01 ; * * * p<0.001 ; * * * * p<0.0001)$. 
bioRxiv preprint doi: https://doi org/101101/2020 10 10.328146; this version posted January 5, 2021. The copyright holder for this preprint (which was not certified by peer review) is the author/funder, who has granted bioRxiv a license to display the preprint in perpetuity. It is made available under aCC-BY-NC-ND 4.0 International license.

a

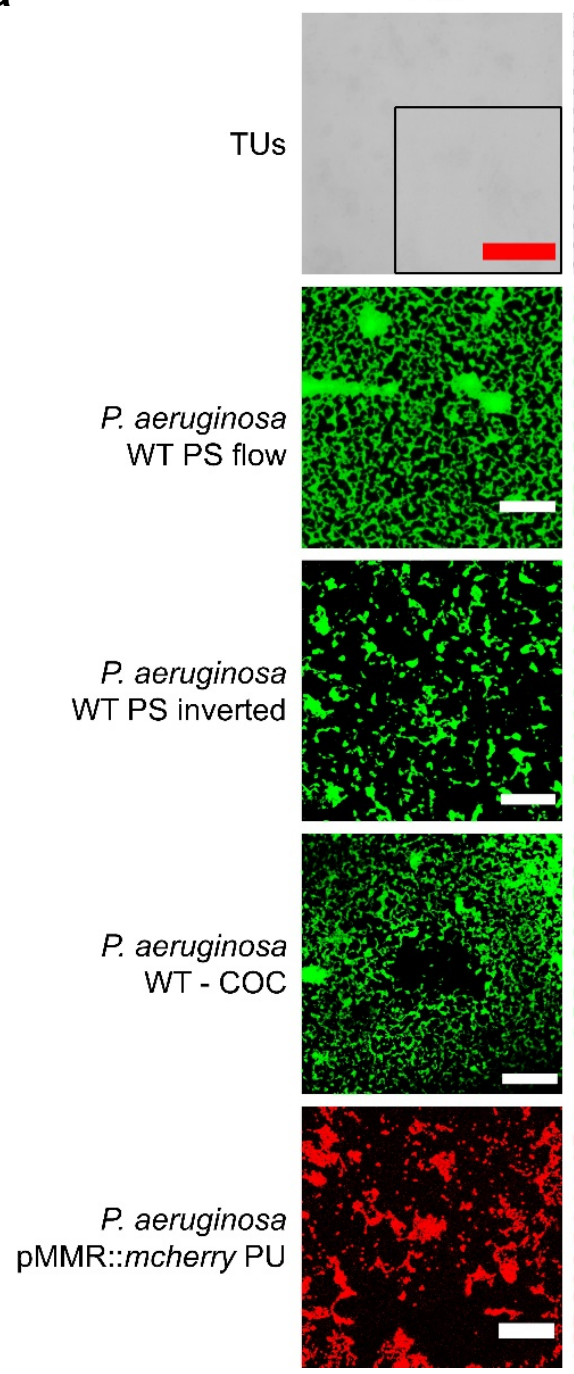

1228 Pro
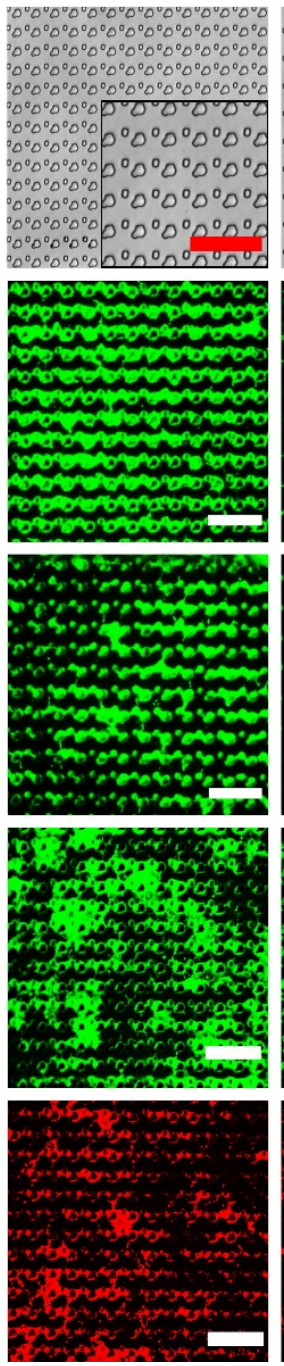

2327 Pro
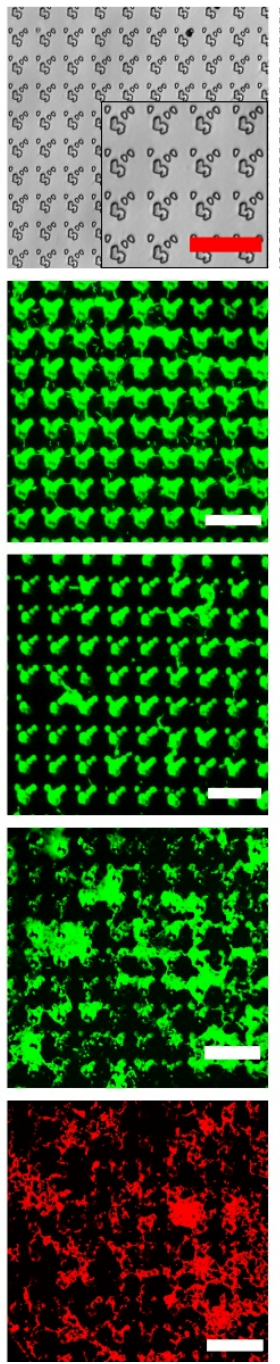

0709 Anti

1307 Anti
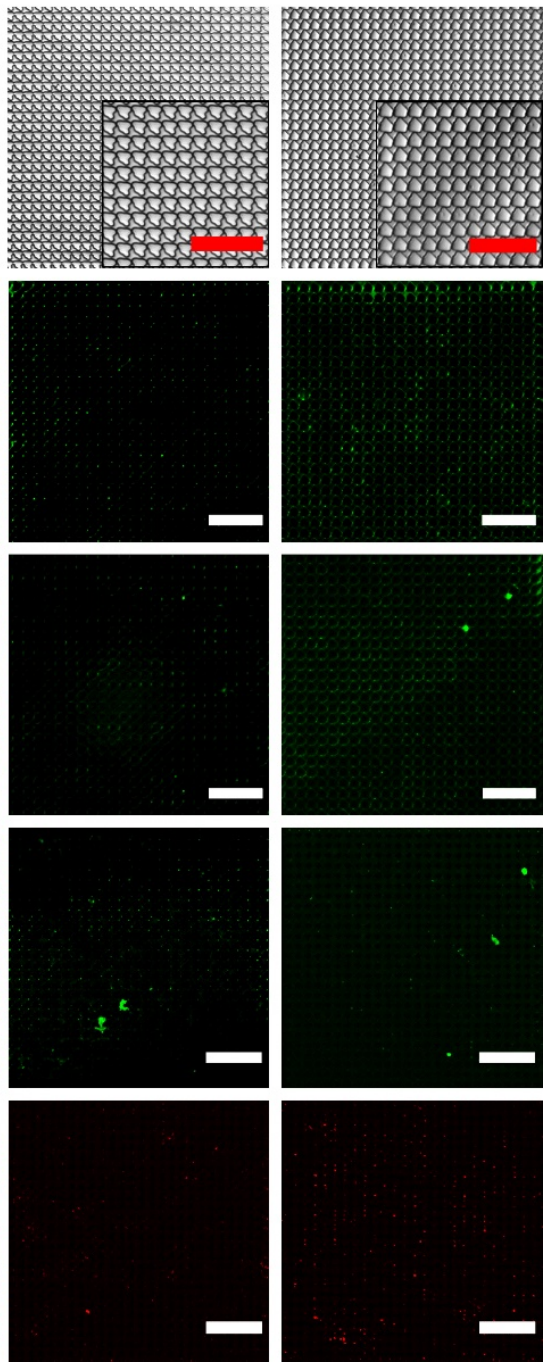
b

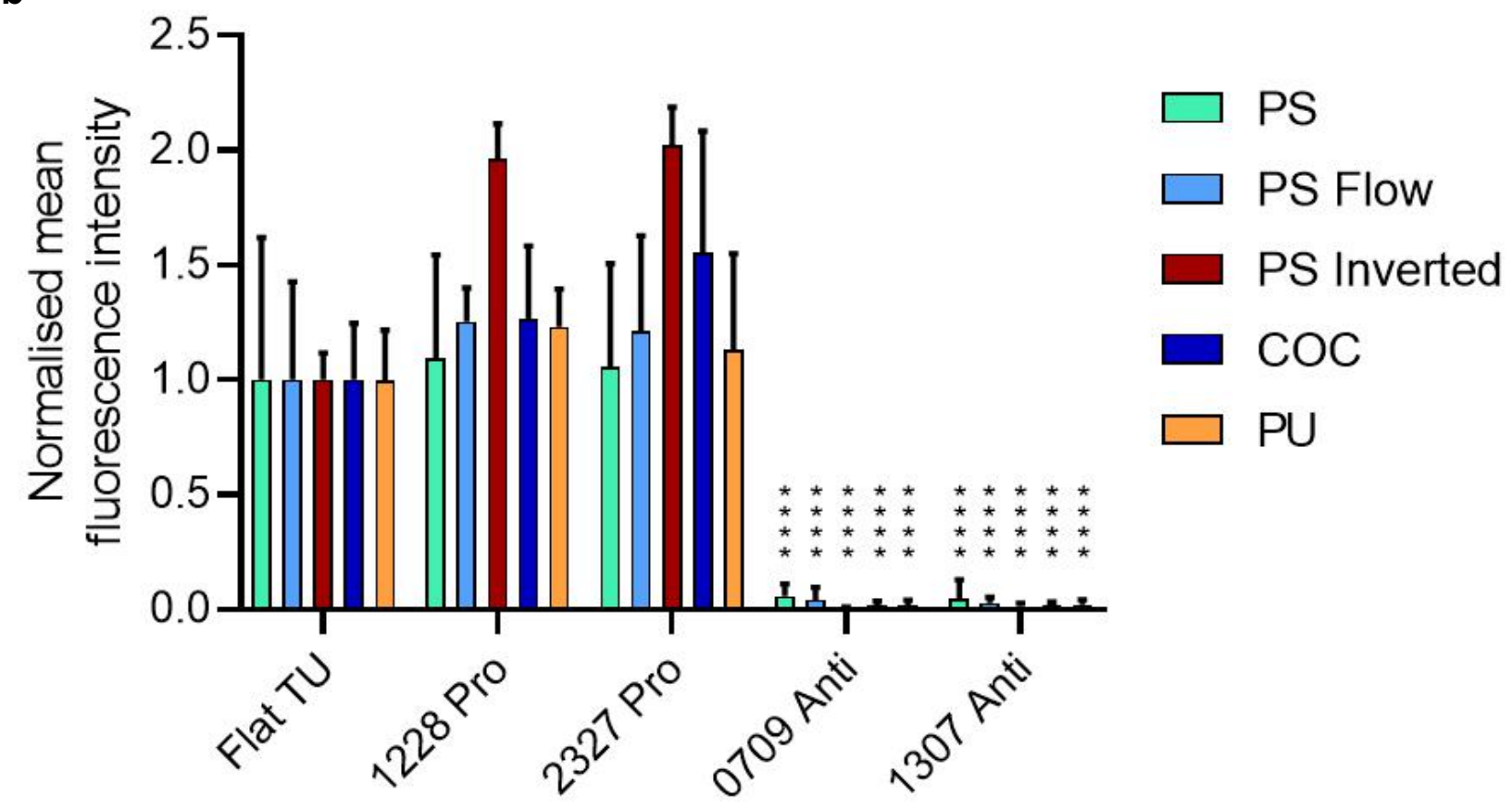

C

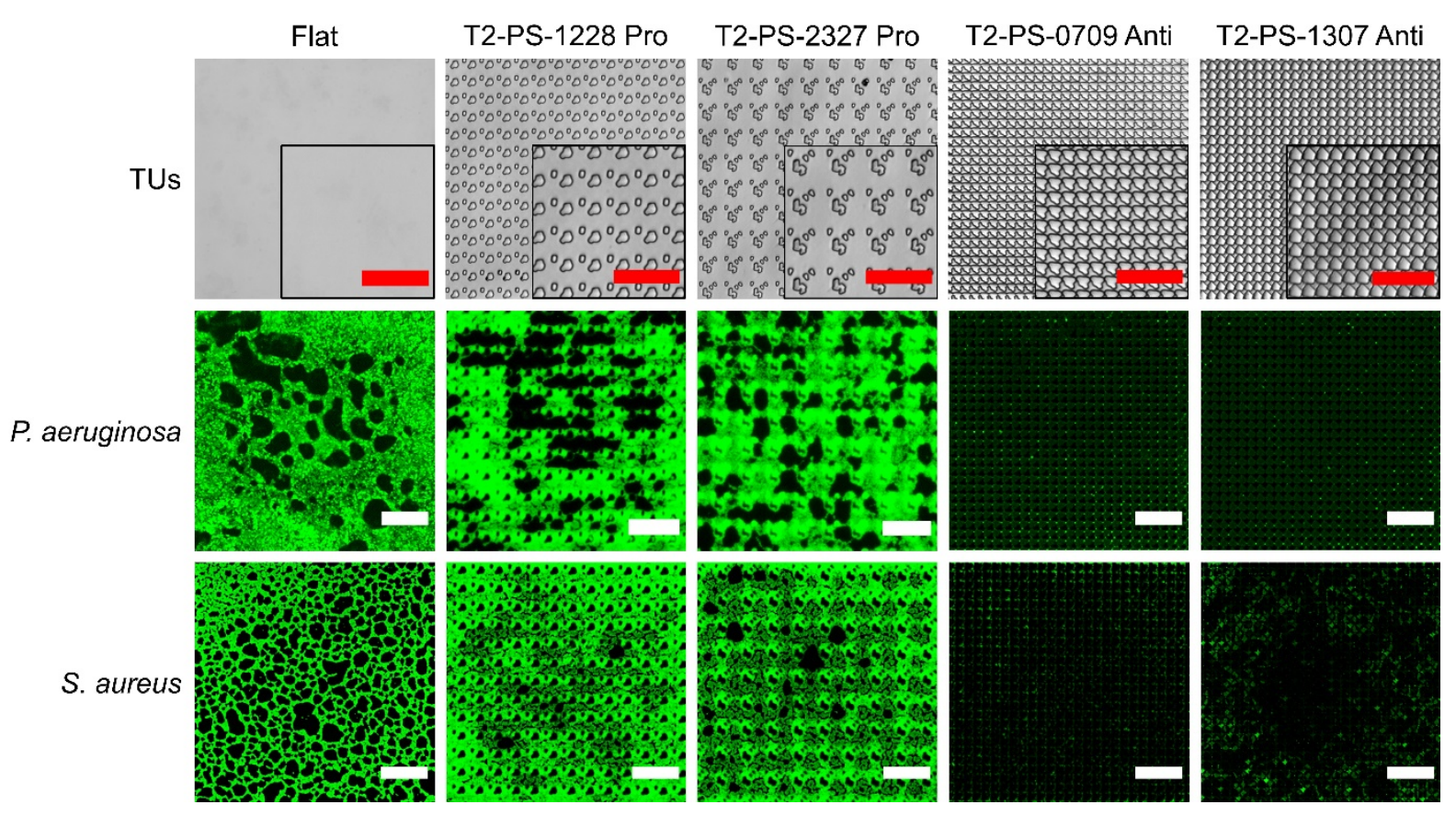


d

\section{$P$. aeruginosa}

S. aureus

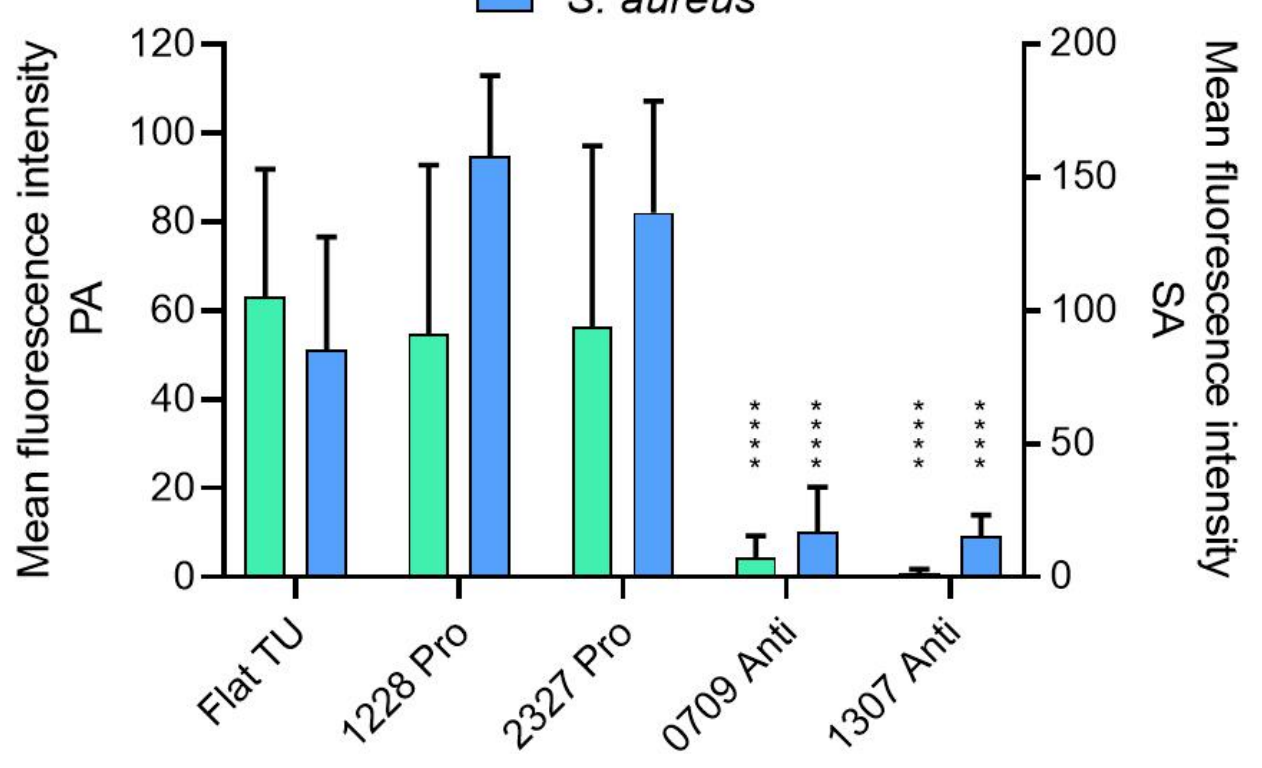

Figure 4. (a) Representative images of $P$. aeruginosa pME6032: :mcherry (red) and $P$. aeruginosa wildtype stained with Syto9 fluorescent dye (green) grown for $4 \mathrm{~h}$ on flat, pro- or anti-attachment TUs (bright field images shown in top row) moulded from polystyrene (PS), polyurethane (PU) or cyclic olefin copolymer (COC). P. aeruginosa wildtype attachment on upside down oriented TUs (inverted) and under flow conditions is shown for PS TUs. (b) Quantification of mean normalised fluorescence intensity of $P$. aeruginosa incubated under conditions described above. (c) Representative images of $P$. aeruginosa and $S$. aureus biofilms on flat, pro and anti-attachment PS topographies after $24 \mathrm{~h}$ incubation under static conditions. (d) Quantification of mean fluorescence intensity for $P$. aeruginosa and $S$. aureus biofilms shown in (c). Scale bar: $50 \mu \mathrm{m}$. Data shown are mean $\pm S D, n \geq 5$. Statistical analysis was done using a two-way ANOVA with Dunnett's multiple comparisons test $(* p<0.05 ; * * p<0.01 ; * * * p<0.001 ; * * * * p<0.0001)$. 
a

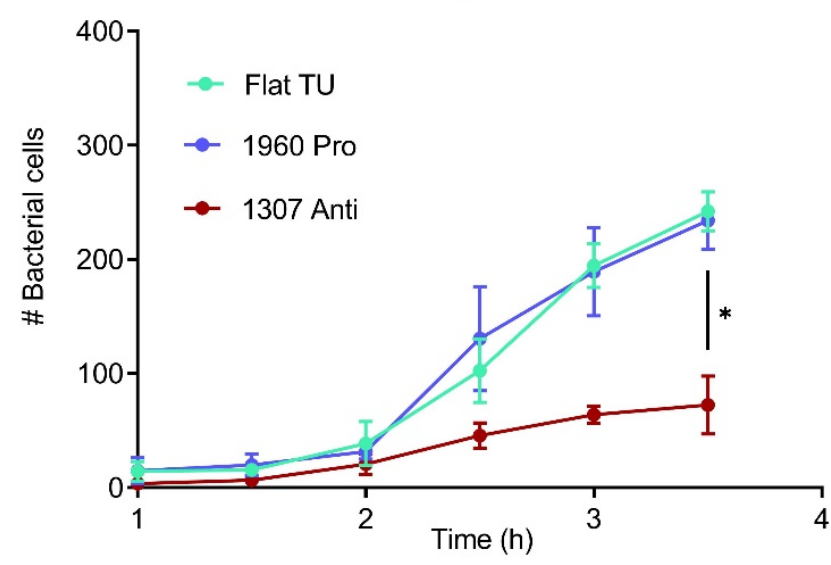

b

S. aureus

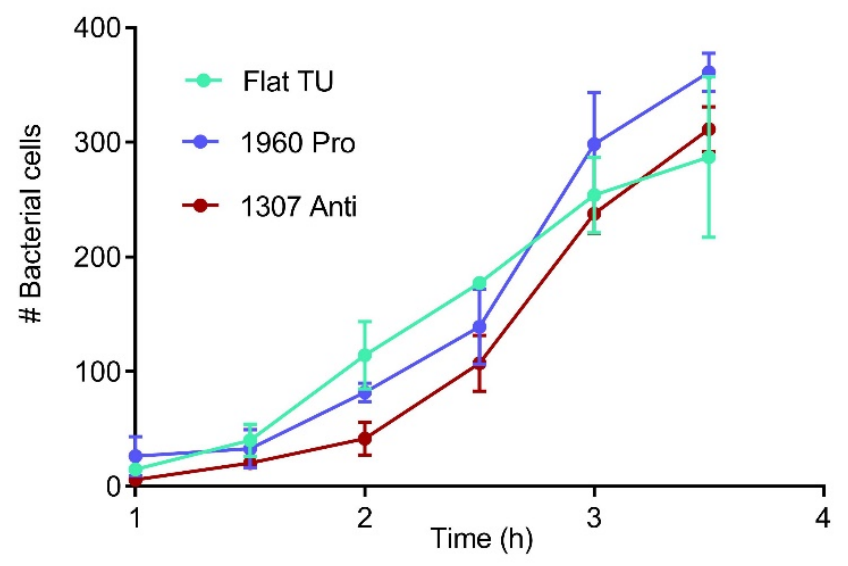

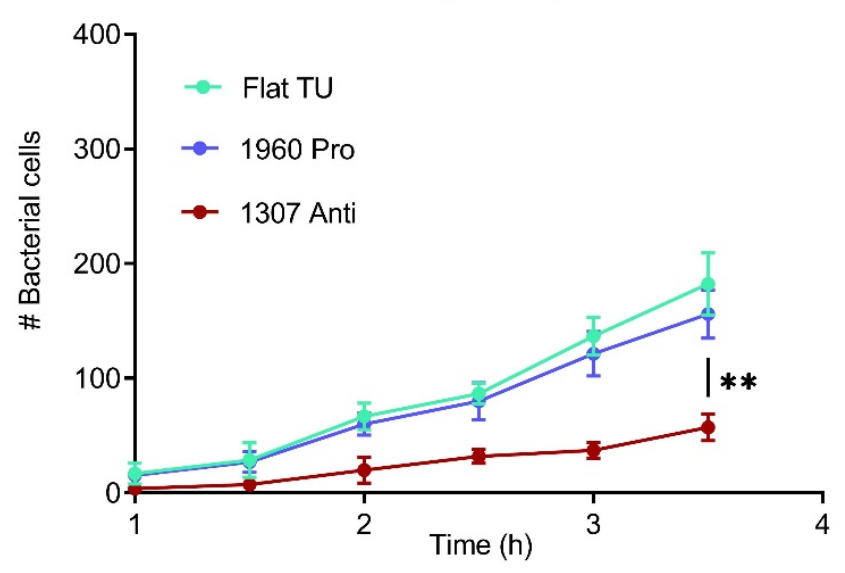

d

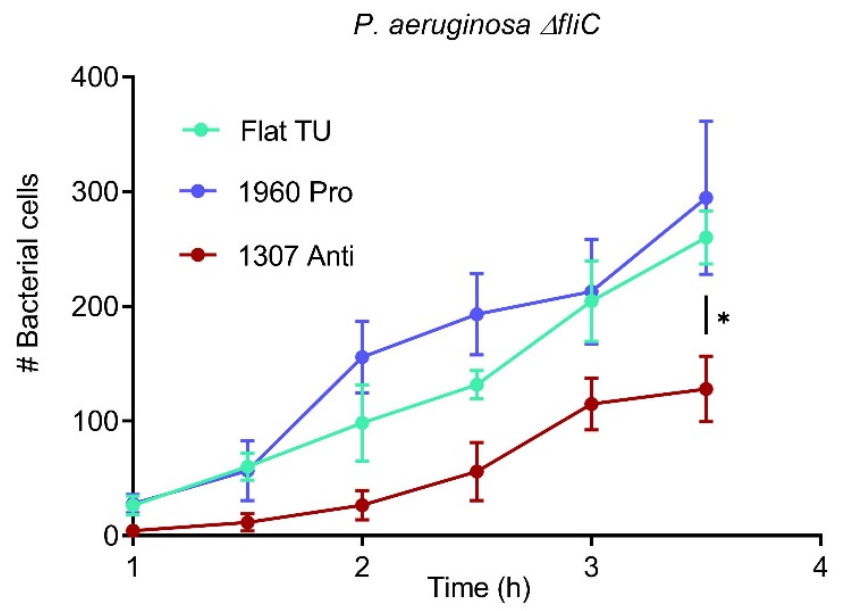

e

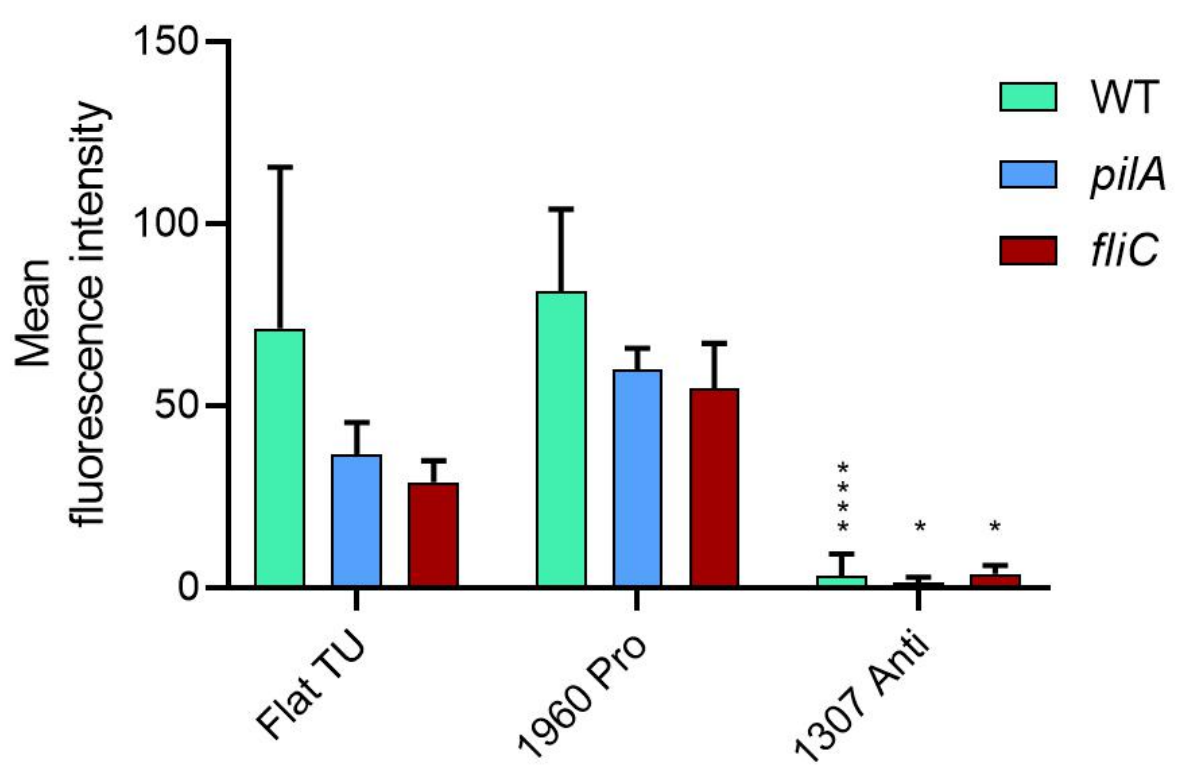


bioRxiv preprint doi: https://doi.org/10.1101/2020 10.10.328146; this version posted January 5 , 2021. The copyright holder for this preprint (which was not certified by peer review) is the author/funder, who has granted bioRxiv a license to display the preprint in perpetuity. It is made available under aCC-BY-NC-ND 4.0 International license.

f

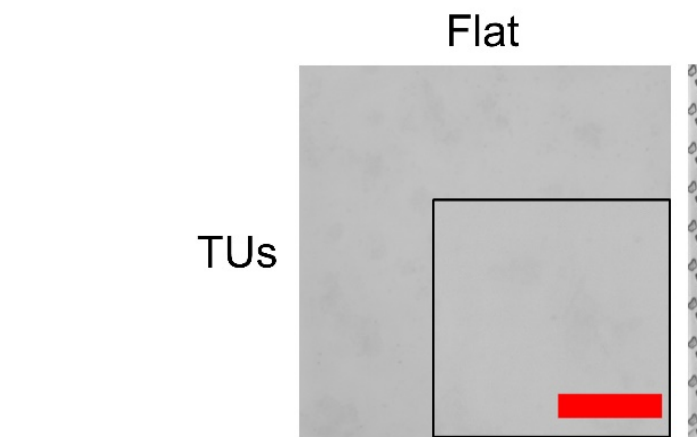

T2-PS-1960 Pro

T2-PS-1307 Anti
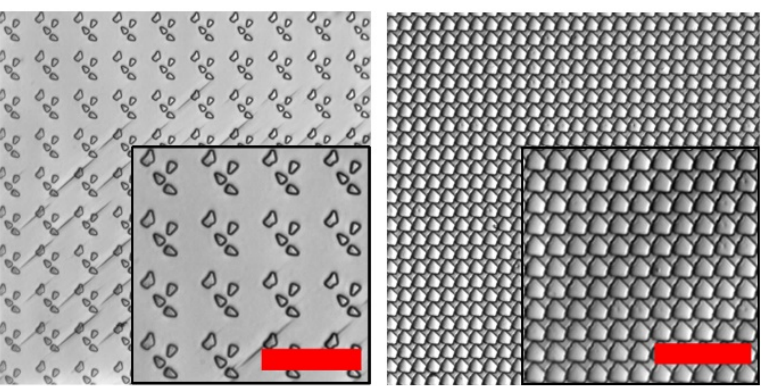

$P$. aeruginosa WT
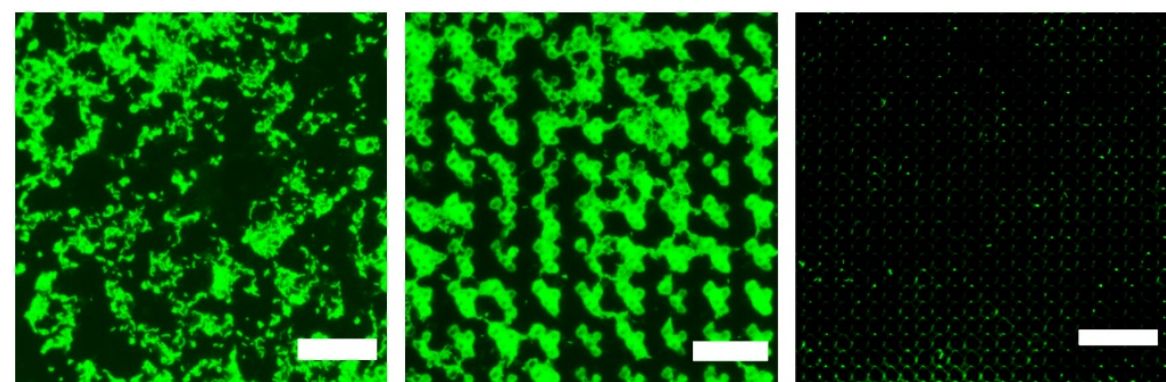

$P$. aeruginosa
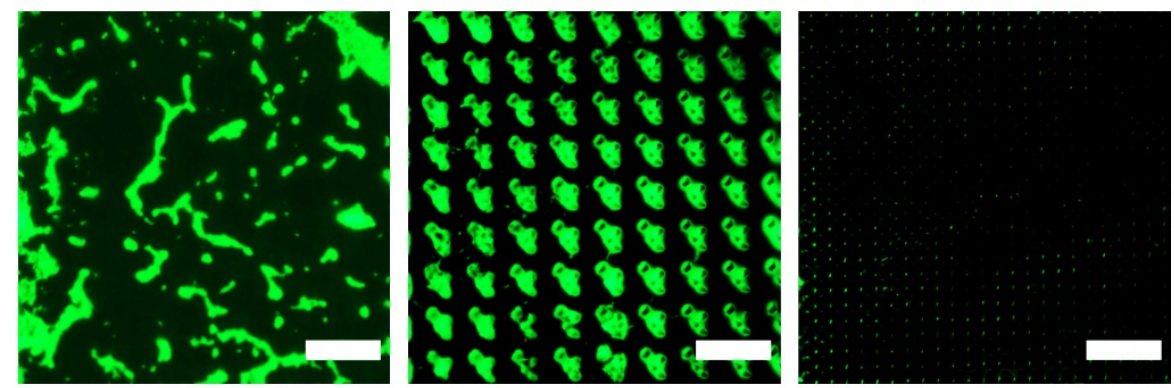

$P$. aeruginosa
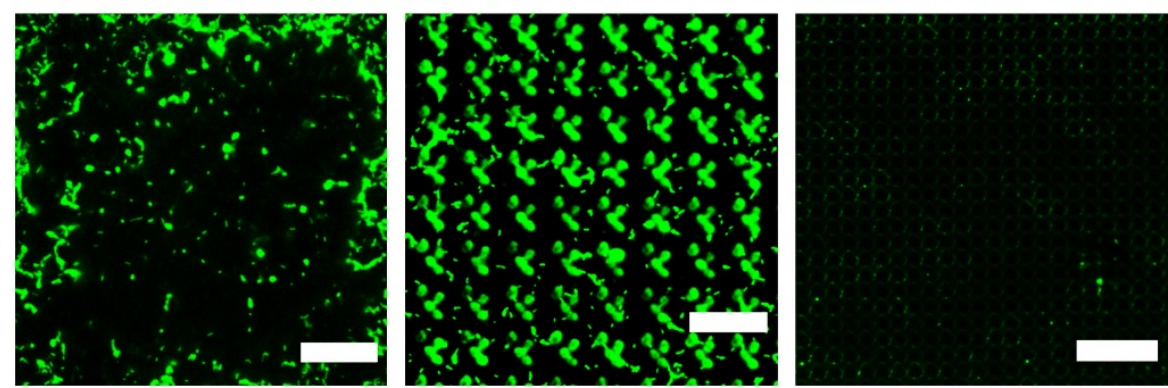

g

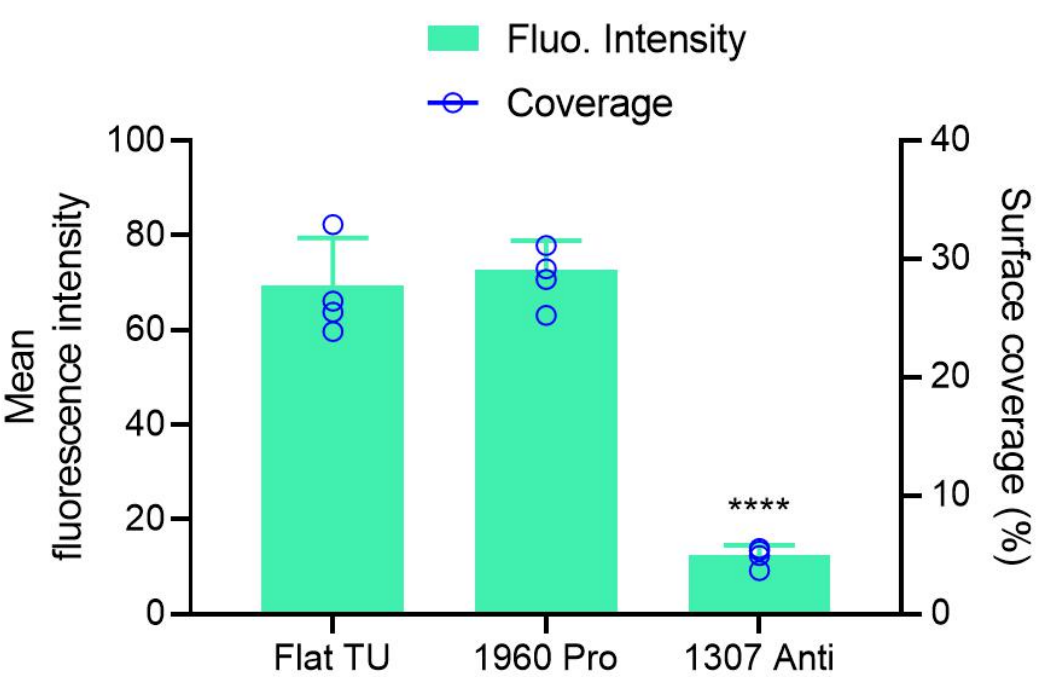


Figure 5. Early stage $P$. aeruginosa and $S$. aureus wildtype and $P$. aeruginosa motility mutant colonization of and c-di-GMP production on, flat, pro- (T2-PS-1960) and anti-attachment (T2-PS1307) TUs after $4 \mathrm{~h}$ incubation in static conditions. (a) $P$. aeruginosa wildtype, (b) $S$. aureus, (c) $P$. aeruginosa $\triangle$ pilA, (d) and $P$. aeruginosa $\triangle$ flic. (e) Mean fluorescence intensity of $P$. aeruginosa wildtype, $\triangle$ pilA and $\triangle$ fliC cells attached to each TU. (f) Representative fluorescent images showing $P$. aeruginosa wildtype, $\Delta$ pilA and $\Delta f l i C$ mutants attached to each TU. (g) Quantitative fluorescence output from $P$. aeruginosa transformed with the cdrA::gfp fusion as a reporter for cdi-GMP production. Data are presented as both fluorescence intensity and surface coverage. Scale bar: $50 \mu \mathrm{m}$. Data shown are mean $\pm S D, n \geq 4$. Statistical analysis was done using a two-way ANOVA with Dunnett's multiple comparisons test $(* \mathrm{p}<0.05 ; * * \mathrm{p}<0.01 ; * * * \mathrm{p}<0.001 ; * * * *$ $\mathrm{p}<0.0001)$. 